\title{
Numerical Investigation of the Resistance of a Zero-Emission Full-Scale Fast Catamaran in Shallow Water
}

\author{
Guangyu Shi ${ }^{1}$, Alexandros Priftis ${ }^{1}$ (D), Yan Xing-Kaeding ${ }^{2}$, Evangelos Boulougouris ${ }^{1, *(D)}$, \\ Apostolos D. Papanikolaou ${ }^{3}$ (D) Haibin Wang ${ }^{1}(\mathbb{D})$ and Geoff Symonds ${ }^{4}$ \\ 1 Maritime Safety Research Centre (MSRC), Department of Naval Architecture, Ocean and Marine Engineering, \\ University of Strathclyde, Glasgow G4 0LZ, UK; Guangyu.Shi@strath.ac.uk (G.S.); \\ Alexandros.Priftis@strath.ac.uk (A.P.); haibin.wang.100@strath.ac.uk (H.W.) \\ 2 Computational Fluid Dynamics Department, Hamburg Ship Model Basin (HSVA), 22305 Hamburg, Germany; \\ Xing-Kaeding@hsva.de \\ 3 Ship Design Laboratory, National Technical University of Athens (NTUA), 15780 Athens, Greece; \\ papa@deslab.ntua.gr \\ 4 Uber Boat by Thames Clippers, London E14 0JY, UK; geoff.symonds@thamesclippers.com \\ * Correspondence: evangelos.boulougouris@strath.ac.uk
}

check for updates

Citation: Shi, G.; Priftis, A.; Xing-Kaeding, Y.; Boulougouris, E.; Papanikolaou, A.D.; Wang, H.; Symonds, G. Numerical Investigation of the Resistance of a Zero-Emission Full-Scale Fast Catamaran in Shallow Water. J. Mar. Sci. Eng. 2021, 9, 563. https://doi.org/10.3390/jmse9060563

Academic Editors: Javad Mehr and Abbas Dashtimanesh

Received: 24 April 2021

Accepted: 19 May 2021

Published: 23 May 2021

Publisher's Note: MDPI stays neutral with regard to jurisdictional claims in published maps and institutional affiliations.

Copyright: (c) 2021 by the authors. Licensee MDPI, Basel, Switzerland. This article is an open access article distributed under the terms and conditions of the Creative Commons Attribution (CC BY) license (https:/ / creativecommons.org/licenses/by/ $4.0 /)$.

\begin{abstract}
This paper numerically investigates the resistance at full-scale of a zero-emission, highspeed catamaran in both deep and shallow water, with the Froude number ranging from 0.2 to 0.8. The numerical methods are validated by two means: (a) Comparison with available model tests; (b) a blind validation using two different flow solvers. The resistance, sinkage, and trim of the catamaran, as well as the wave pattern, longitudinal wave cuts and crossflow fields, are examined. The total resistance curve in deep water shows a continuous increase with the Froude number, while in shallow water, a hump is witnessed near the critical speed. This difference is mainly caused by the pressure component of total resistance, which is significantly affected by the interaction between the wave systems created by the demihulls. The pressure resistance in deep water is maximised at a Froude number around 0.58, whereas the peak in shallow water is achieved near the critical speed (Froude number $\approx 0.3$ ). Insight into the underlying physics is obtained by analysing the wave creation between the demihulls. Profoundly different wave patterns within the inner region are observed in deep and shallow water. Specifically, in deep water, both crests and troughs are generated and moved astern as the increase of the Froude number. The maximum pressure resistance is accomplished when the secondary trough is created at the stern, leading to the largest trim angle. In contrast, the catamaran generates a critical wave normal to the advance direction in shallow water, which significantly elevates the bow and creates the highest trim angle, as well as pressure resistance. Moreover, significant wave elevations are observed between the demihulls at supercritical speeds in shallow water, which may affect the decision for the location of the wet deck.
\end{abstract}

Keywords: fast catamaran; shallow water resistance; full-scale CFD

\section{Introduction}

Low-carbon, environmentally-friendly maritime transport is playing an important role in reducing the emission of greenhouse gases and building a sustainable future. The need for technological innovations in the design of zero-emission ships is posing challenges for the maritime industry in the coming decades. The research presented herein was conducted in the European Commission (EC) funded research project TrAM (Transport: Advanced and Modular, https: / / tramproject.eu/ (accessed on 23 April 2021)), which aims at designing and manufacturing battery-powered fast catamarans operating in coastal areas and inland waterways by implementing modular design and production methods. Given the significant lower specific energy content of batteries compared to conventional fuels [1], the design of zero-emission high-speed marine vehicles poses unique challenges 
and limitations which are tackled within the TrAM project. These include the selection of the appropriate battery technology and specification, safety considerations, and of course, multi-objective hull form optimisation in the presence of shallow water effects [1-4]. The present study is focused on the battery-driven, zero-emission 'TrAM London Demonstrator', designed for The Thames River. It examines the hydrodynamic performance of the preliminary design of this high-speed catamaran in shallow water as it affects directly the rate by which the vessel consumes the stored energy. Therefore, it verifies and validates the computational methods employed in the hydrodynamic optimisation of the hull form.

Catamarans, due to their favourable performance in efficiency and stability at high speeds, have been widely studied experimentally, theoretically and numerically over the past decades [5-7]. A series of model tests were carried out by Insel and Molland [8] and Molland et al. [9] investigating the calm water resistance of fast catamarans with symmetrical demihulls, whereas Zaraphonitis et al. [10] have studied asymmetrical demihulls. Their studies emphasised the effects of demihull dimensions and separation distance on the resistances and motions of the catamarans over a wide range of Froude numbers $(0.2 \leq F n \leq 1.0)$. van't Veer [11] also experimentally investigated the resistance and dynamic motion characteristics using Delft 372 catamaran, which has been used as a benchmark for numerical simulations. Later experimental studies with Delft 372 catamaran were concentrated on the hydrodynamic interference between demihulls [12,13] and seakeeping [14-16]. Broglia et al. [13] carried out experimental work examining the interference effects between the demihulls of a catamaran. It was found that positive inference only occurred within a narrow range of testing conditions, and the interaction between demihulls could increase the total resistance by up to $30 \%$. The interference effects were less strong at very low and very high Froude numbers $(F n<0.3$ or $F n>0.7)$. Zaraphonitis et al. [17] studied the optimisation of the hull shape with regards to powering and wash for a high speed catamaran. Souto-Iglesias et al. [18] also experimentally investigated the interference phenomenon of a catamaran and compared the wave systems created by the catamaran and the corresponding monohull. They concluded that the non-centred inner wave cuts are also important evidence for the analysis of wave interference. Later, Souto-Iglesias et al. [19] further studied the influence of demihull separation and testing condition on the interference resistance of a Series 60 catamaran and found that the free sinkage-trim condition enhanced both the favourable and unfavourable interference effects compared with fixed condition cases. Danısman [20] found that the wave interference resistance between the demihulls could be considerably reduced by placing an optimised Centrebulb, which led to a favourable secondary wave interaction.

With the fast development of computer science and numerical methods, computational fluid dynamics (CFD) has become a feasible approach with sufficient accuracy to investigate ship hydrodynamics [21]. Various CFD solvers have been applied to examine the calm water resistance and seakeeping of both monohulls [22-24] and multihulls [25-29]. A combined experimental and numerical study was carried out by Zaghi et al. [30] to analyse the interference effects between the demihulls and the dependency on the separation of a high-speed catamaran. Two humps were found in the total resistance coefficient curves, and the second one was much higher, corresponding to a stronger interference. Besides, a smaller separation distance led to a stronger interaction and a larger speed where the peak occurred. Broglia et al. [31] conducted a numerical analysis on the interference phenomena between the demihulls of the catamaran with emphasis on the validation of the CFD code and the Reynolds number effect. It was found that the numerical results agreed very well with the experiment in terms of resistance and wave cuts, and the dependency on the scale effect was rather weak. He et al. [32] computationally investigated the effects of Froude number, and demihull separation distance on the resistance and motion of the catamaran. They found that the resistance coefficient became higher at smaller separation distances, indicating stronger interference between the demihulls. Besides, the strongest demihull interaction occurred when Froude number is between 0.45 and 0.65 $(0.45<F n<0.65)$. When the Froude number is below 0.45 or above 0.65 , the variation of 
the separation distance had a negligible effect on the resistance, as well as the sinkage and trim of the catamaran. Haase et al. [33] proposed a novel CFD-based method for predicting full-scale ship resistance, which relied on the results of the model test experiment and CFD simulation at both model-scale and full-scale Reynold number. Farkas et al. [34] carried out a numerical study on the interference of resistance components for a Series 60 catamaran at medium Froude numbers, where the interference factor was decomposed into viscous interference and wave interference. They found that the form factor of the catamaran was independent of the Froude number, but decreased to the value of the monohull when the separation distance became larger. It was also observed that the viscous interference factor was independent of the Froude number, but relied on the separation ratio of the catamaran.

The shallow water effects must be considered when designing ships for restricted waterways (e.g., inland rivers, canals). Previous studies regarding shallow water effects for monohulls [35-39] revealed that the depth Froude number $\left(F n_{H}=U / \sqrt{g H}\right.$, where $U$ is the ship speed, $g$ is gravity acceleration and $H$ is the water depth) is playing a key role in determining the performance of the vessel. A ship moving near the critical depth Froude number $\left(F n_{H}=1.0\right)$ will experience a surge in total resistance coefficient and drastic changes in motions and wave patterns, which should be taken into account when passing through shallow water areas. In terms of catamarans operating in shallow water, several experimental and numerical studies are also available [40-43]. Molland et al. [44,45] experimentally investigated the resistance of a series of fast displacement catamarans in shallow water. Similar to monohulls, the catamarans experienced large increases in total resistance and wave elevation, and significant changes in sinkage and trim near the critical depth Froude number. The resistance increase was higher for the smaller water depth. Gourlay [46] theoretically predicted the sinkage and trim of various catamaran configurations in shallow water. It was found that the maximum sinkage and trim occurred at the trans-critical speed range. Lee et al. [47] designed and tested the shallow water behaviours of a small catamaran and further investigated the influence of the separation ratio between the demihulls on the resistance characteristics. The residual resistance coefficient surged near the critical depth Froude number and the sinkage and trim also varied significantly in the critical region. Castiglione et al. [48] studied the interference effects between the demihulls of a high-speed catamaran in shallow water using a CFD method. They concluded that for all separation ratios, the total resistance coefficients were significantly increased, due to shallow water effects, with peaks achieved near the critical depth Froude number. However, at extreme subcritical and supercritical speeds, the total resistance coefficients in shallow water became smaller than the values of corresponding deepwater cases. It was also found that the interference factor reached its peak values around the critical speed and increased for smaller separation distances. Moreover, the sinkage and trim were also increased compared with deep water values and maximised at the critical speed.

Despite the extensive studies on the calm water resistance and interference of highspeed catamarans, CFD simulations on full-scale fast catamarans in shallow water are still rare. As aforementioned, the work in the present paper is part of the ongoing TrAM Project (https:/ / tramproject.eu/ (accessed on 23 April 2021)), and the objectives of the current study are twofold: (1) Validate the numerical methods and setups that will be employed in the hull optimisation stage, (2) investigate the shallow water effect on the calm water resistance, sinkage, trim and wave creation of the full-scale London Demonstrator catamaran using a CFD method. The rest of this paper is organised as follows: In Section 2, the geometry of the London Demonstrator and parameters used for analysis are presented. The computational methods are introduced in Section 3, and they are validated in Section 3.4. In the Section 4, the numerical results are given. The conclusions are drawn in the Section 5.

\section{Geometry and Parameters}

\subsection{Catamaran Geometry and Dimensions}

The London Demonstrator catamaran investigated in the present work is designed by the Maritime Safety Research Centre (MSRC) at the University of Strathclyde, which is 
a partner at the ongoing EU funded project TrAM (https: / tramproject.eu/ (accessed on 23 April 2021)). The London Demonstrator is designed for The Thames River as a batterydriven, zero-emission passenger ferry. As the catamaran is still at the initial design stage, the geometry illustrated in Figure 1 is selected as a showcase validating the numerical methods and examining the shallow water effect. Some main dimensions of the London Demonstrator are summarised in Table 1, where $L_{p p}$ is the length between perpendiculars. The vertical and longitudinal centres of gravity are measured as the distances below the waterline and ahead of the aft perpendicular of the catamaran, respectively. The gyration radii used to calculate the moment of inertia for pitch motion is $0.25 L_{p p}$.

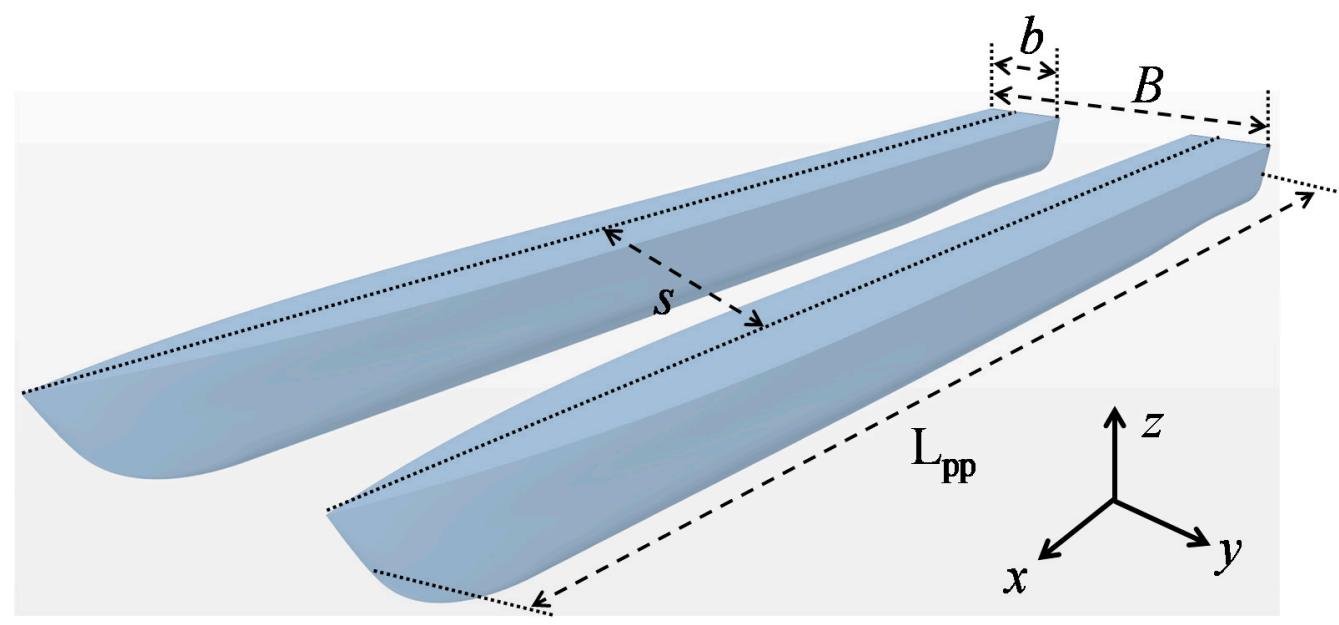

Figure 1. The geometry of the London demonstrator.

Table 1. Main dimensions of the TrAM London Demonstrator catamaran.

\begin{tabular}{ccc}
\hline Dimension & Symbol & Value \\
\hline Demihull breadth & $b / L_{p p}$ & 0.068 \\
Separation & $s / L_{p p}$ & 0.187 \\
Draught & $T / L_{p p}$ & 0.033 \\
Depth/draught & $H / T$ & 2.0 \\
Vertical centre of gravity & $V C G / L_{p p}$ & 0.012 \\
Longitudinal centre of gravity & $L C G / L_{p p}$ & 0.447 \\
\hline
\end{tabular}

\subsection{Parameters for Analysis}

In ship hydrodynamics, Froude number is an important non-dimensional parameter measuring the speed of the vessel, which is defined as:

$$
F n=\frac{U}{\sqrt{g L_{p p}}}
$$

where $U$ is the ship speed relative to the incoming flow, $g$ is gravity acceleration. For ships advancing in shallow waterways, the Froude number defined based on the water depth is playing a significant role in determining the ship hydrodynamics:

$$
F n_{H}=\frac{U}{\sqrt{g H}}
$$

The hydrodynamic performance of the TrAM London Demonstrator is analysed by examining its total resistance $\left(R_{T}\right)$, sinkage $(\sigma)$ and trim $(\theta)$. The total resistance is decomposed into the frictional component $\left(R_{F}\right)$ and pressure component $\left(R_{P}\right)$, i.e., $R_{T}=R_{F}+R_{P}$. The sinkage and trim are measured based on the centre of mass of the catamaran, and they defined as positive when the catamaran goes down and the bow moves up, respectively. Moreover, 
the resistance coefficients are also used for analysis. The total resistance coefficient is defined as

$$
C_{T}=\frac{R_{T}}{0.5 \rho U^{2} S}
$$

Similarly, the frictional and pressure resistance coefficients can be formulated as

$$
\begin{aligned}
C_{F} & =\frac{R_{F}}{0.5 \rho U^{2} S} \\
C_{P} & =\frac{R_{P}}{0.5 \rho U^{2} S}
\end{aligned}
$$

where $\rho$ is the water density, $U$ is the moving speed of the catamaran and $S \in\left(S_{s w}, S_{d w}\right)$ is the wetted surface area, where $S_{s w}$ and $S_{d w}$ are the static and dynamic wetted surface areas, respectively. The frictional resistance coefficient can also be estimated by the ITTC 1957 correlation line formula

$$
C_{F, I T T C}=\frac{0.075}{\left[\log _{10}(R e)-2\right]^{2}}
$$

\section{Methodology}

\subsection{Computational Methods}

\subsubsection{Flow Simulation}

The unsteady incompressible turbulent flow in the present study is simulated by solving the unsteady Reynolds-Averaged Navier-Stokes (URANS) equations. The corresponding continuity and momentum equations can be formulated as [49]

$$
\begin{gathered}
\frac{\partial\left(\rho \overline{u_{i}}\right)}{\partial x_{i}}=0 \\
\frac{\partial\left(\rho \overline{u_{i}}\right)}{\partial t}+\frac{\partial}{\partial x_{j}}\left(\rho \overline{u_{i} u_{j}}+\rho \overline{u_{i}^{\prime} u_{j}^{\prime}}\right)=-\frac{\partial \bar{p}}{\partial x_{i}}+\frac{\partial \overline{\tau_{i j}}}{\partial x_{j}}=0
\end{gathered}
$$

where $\rho$ is the fluid density, $x_{i}$ and $x_{i}$ are the components of the position vector in Cartesian coordinate, $\overline{u_{i}}$ and $\overline{u_{j}}$ are the components of the mean velocity vector, $\overline{u_{i}^{\prime} u_{j}^{\prime}}$ is the Reynolds stresses and $\bar{p}$ is the mean pressure. $\overline{\tau_{i j}}$ are the components of the mean viscous stress tensor, which can be written as

$$
\overline{\tau_{i j}}=\mu\left(\frac{\partial \overline{u_{i}}}{\partial x_{j}}+\frac{\partial \overline{u_{j}}}{\partial x_{i}}\right)
$$

where $\mu$ is the fluid dynamic viscosity.

The $k-\omega$ SST turbulence model, which has been widely used for marine hydrodynamics [21,29,32], is employed as the closure for Equations (6) and (7). Here, the flow governing equations, including the turbulent model, are solved using a finite volume method implemented in the commercial code Star CCM+14.06. The Semi-Implicit Method for Pressure-Linked Equations (SIMPLE) was used as the solution procedure, where the continuity and momentum equations are solved sequentially and then coupled via a predictor-corrector approach. The spatial discretisation was achieved using a second-order scheme, while a first-order scheme was employed for temporal discretisation, since we are only focused on the final converged equilibrium state.

\subsubsection{Free Surface Capturing}

For marine hydrodynamics, the appropriate capture of the free surface is of great importance to accurately predict the wave height. In the present work, the volume of fluid (VOF) method in combination with the High-Resolution Interface Capturing (HRIC) scheme was adopted to calculate the wave elevation induced by the motion of the catamaran. To avoid the wave's reflection at the boundaries of the computational domain, a wave 
forcing method was used at relevant boundaries to guarantee that the wave is completely damped out when it reaches the domain boundary. The wave forcing length and relevant boundaries are illustrated in Figure 2.

(a)

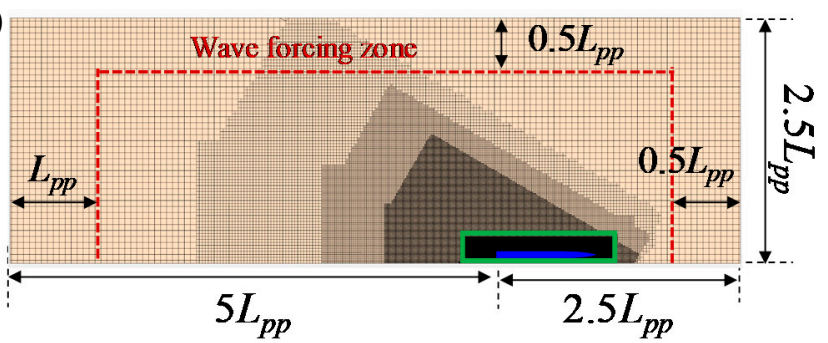

(c)

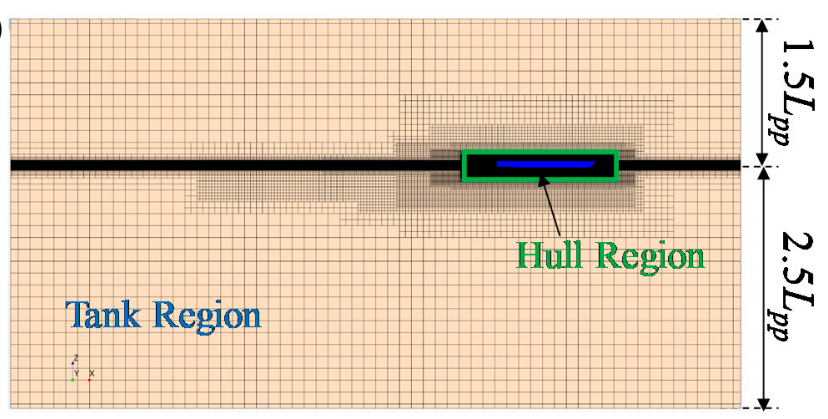

(b)

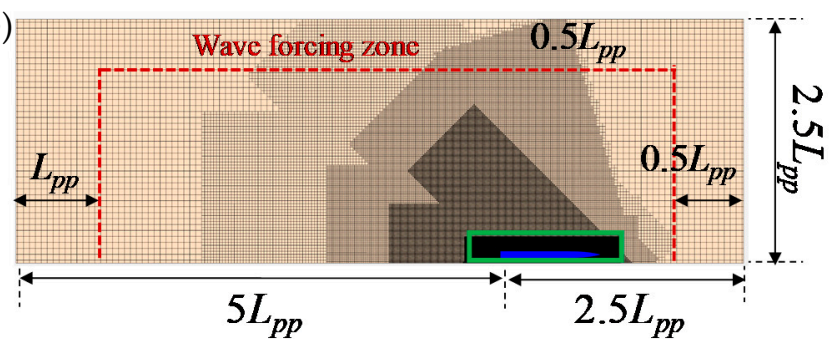

(d)

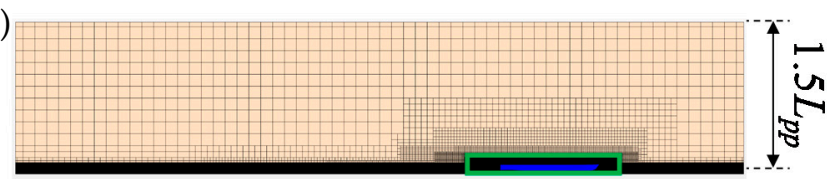

Figure 2. Computational meshes and domain dimensions used for deep water $(\mathbf{a}, \mathbf{c})$ and shallow water cases $(\mathbf{b}, \mathbf{d})$.

\subsubsection{Dynamic Trim and Sinkage}

As the catamaran is advancing in the water, the surface of the hull will interact with the surrounding water, leading to a fluid-body interaction problem. In the present study, only the heave and pitch motions were allowed, while the rest degrees of freedom were fixed. The Dynamic Fluid-Body Interaction (DFBI) method provided in Star CCM+ 14.06 package was employed to calculate the sinkage and trim of the catamaran according to the fluid forces and moments acting on the hull surface. As the overset grid strategy was used in the present study, the DFBI method was only applied to the demi-hull and its associated region (see Section 3.2).

\subsubsection{Coordinate System}

In the present simulation, two different coordinate systems are used: An earth-fixed (global) system and a ship-fixed (local) system. The flow simulation was carried out within the earth-fixed coordinate system, and the computed forces and moments were then transformed to the ship-fixed coordinate system whose origin was located at the centre of mass of the catamaran. The equations of the motion were solved based on the latest forces and moments using the DFBI method. The new position and velocity of the hull were then converted back to the earth-fixed system as the boundary condition for the flow simulation. After updating the position of the hull, the connectivity between the two sub-domains in the overset grid method was re-calculated accordingly.

\subsection{Computational Domain and Boundary Conditions}

As the catamaran is geometrically symmetrical about its mid-plane, only one demihull was used for CFD simulation to reduce computational cost. Besides, the overset grid method was employed in the present study, i.e., the entire computational domain was decomposed into two regions: An inner region around the demi-hull (Hull Region) and an outer region forming the virtual tank (Tank Region). Figure 3 shows the two regions and corresponding boundary conditions. The flow variables between the two flow regions were exchanged at the overlapping boundary via linear interpolation. For deep water scenarios, as demonstrated in Figure 2a,b, the Tank Region was extended $1.5 L_{p p}$ in front of the hull and $5 L_{p p}$ behind it. The lower and upper boundaries were $2.5 L_{p p}$ and $1.5 L_{p p}$ away 
from the undisturbed water level, respectively. The side boundary of the Tank Region was $2.5 L_{p p}$ away from the symmetry plane of the catamaran. The velocity inlet condition was applied at the inlet, top, bottom and side boundaries. The pressure outlet condition was used for the outlet boundary. The demi-hull surface was considered as the no-slip wall. To avoid wave refection, a wave forcing method was applied to the regions near the inlet, outlet and side boundaries, as shown in Figure 2a,b. For shallow water scenarios, the size of the Tank Region remained the same as the one used for deep water cases except that the bottom surface was $2.15 \mathrm{~m}$ below the water level, where the slip wall boundary condition was applied. The size of the Hull Region is determined by guaranteeing there are sufficient cells (at least five cell layers) in the overlapping area between the two regions. Besides, the cell size in the overlapping area should be comparable. In the present work, the Hull Region was $0.1 L_{p p}$ in front of the forward perpendicular and $0.15 L_{p p}$ behind the aft perpendicular. The lower and upper boundaries were $0.05 L_{p p}$ away from the waterline, and the side boundaries were $0.05 L_{p p}$ away from the mid-plane of the demihull.
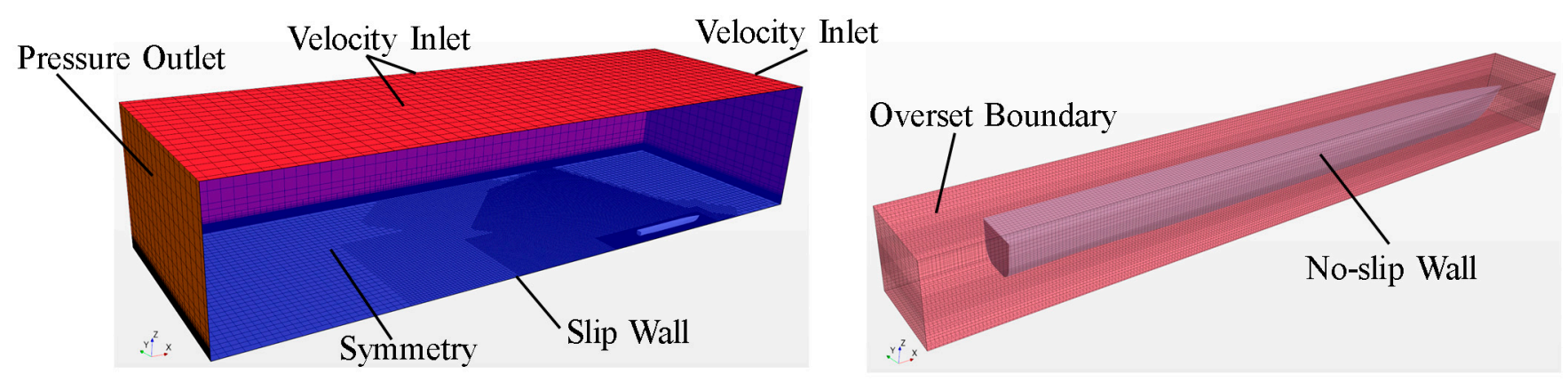

Figure 3. Computational domains (left: Tank Region; right: Hull Region) and boundary conditions.

\subsection{Mesh Generation}

The CFD mesh used in the present study was generated using the automated meshing functionality in Star CCM+14.06, which was comprised of prism cells around the hull and the hexahedral cells in the rest region. The meshes for the Tank Region and Hull Region were generated separately, and an overset grid interface was created between the two regions. Anisotropic mesh refinements were performed in various areas to appropriately capture the flow features. Specifically, three volumetric mesh controls in three different levels were created around the hull. Similarly, such volumetric mesh controls were also generated to capture the Kelvin waves, the flow wakes behind the hull and the free surface, as demonstrated in Figure 2. All mesh refinements were done by setting a target mesh size relative to a base size specified by the user in the automated meshing tool of Star $\mathrm{CCM}+14.06$. The mesh density can also be controlled by varying the value of this base size. Additionally, special attention was given to the overlapping area of the Tank Region and Hull Region when generating the volume mesh. First, the mesh cells within the overlapping region were of similar size. Besides, the overlapping zone was comprised of at least five cell layers in both regions to ensure an accurate and conservative interpolation.

To properly resolve the flow boundary layer, prism mesh layers should be used in the vicinity of the hull. Here, the thickness of the turbulent boundary layer was estimated by

$$
\delta=0.37 L_{p p} / R e^{0.2}
$$

where $R e$ is the Reynolds number based on $L_{p p}$. Ten layers of prism cells were placed within the boundary layer. As the wall function was used in the turbulent model, the distance of the first prism layer to the hull surface was targeted at $y+=100$. Figure 4 demonstrates the computed $y+$ distribution on the hull surface, and it can be observed that for both Froude numbers, the $y+$ values are within the range $(30<y+<300)$ that the wall function can be appropriately applied. 


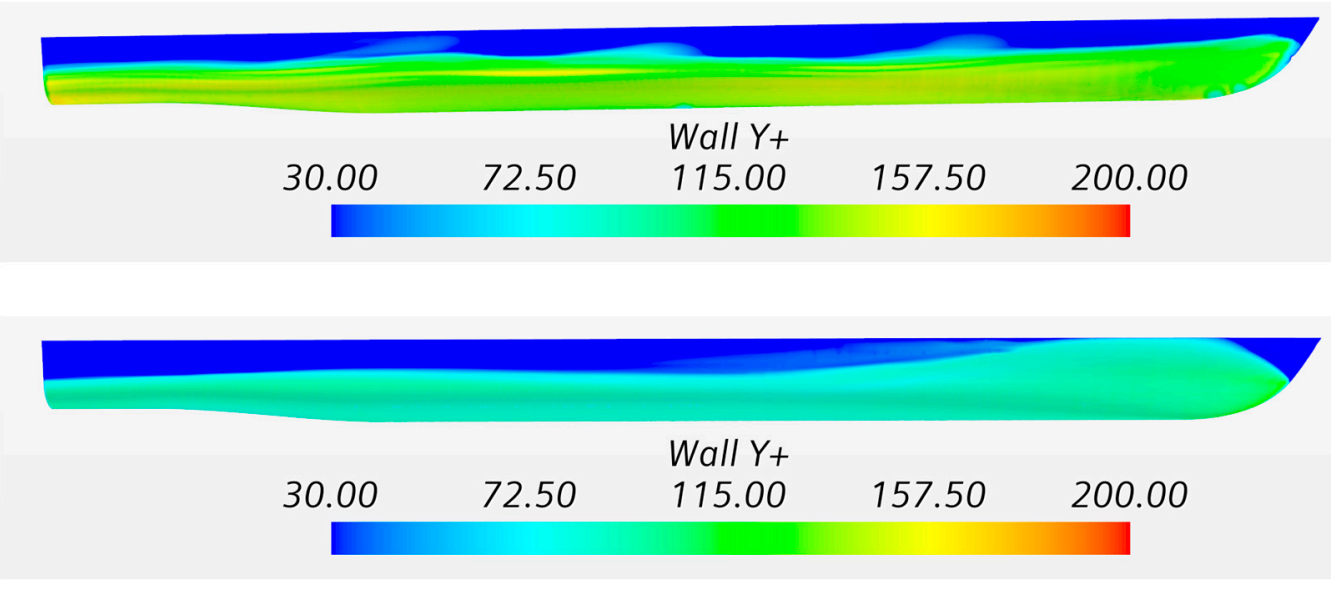

Figure 4. Computed $y+$ distribution on the demihull surface at $F n=0.287$ (upper) and 0.805 (below) in shallow water.

\subsection{Numerical Validation and Verification}

\subsubsection{NPL 4a02 Catamaran}

The first case used to validate the computational methods used in the present study was the NPL 4a02 catamaran from a series of model tests carried out by Molland et al. [9]. Table 2 gives the main particulars of this catamaran. The same computational methods and mesh generation strategies presented in Section 3 were also applied here. The total number of mesh cells used for this validation case was around 4.7 million. Figure 5 demonstrates the total resistance coefficients, sinkage-to-draught ratios and trim angles as functions of the Froude number, from which it is observed that the computed results are in good agreement with the experimental data.

Table 2. Main dimensions of the NPL 4a02 catamaran.

\begin{tabular}{ccc}
\hline Dimension & Symbol & Value \\
\hline Demihull breadth & $b / L_{p p}$ & 0.096 \\
Separation & $s / L_{p p}$ & 0.200 \\
Draught & $T / L_{p p}$ & 0.064 \\
Vertical centre of gravity & $V C G / L_{p p}$ & 0.020 \\
Longitudinal centre of gravity & $L C G / L_{p p}$ & 0.436 \\
\hline
\end{tabular}

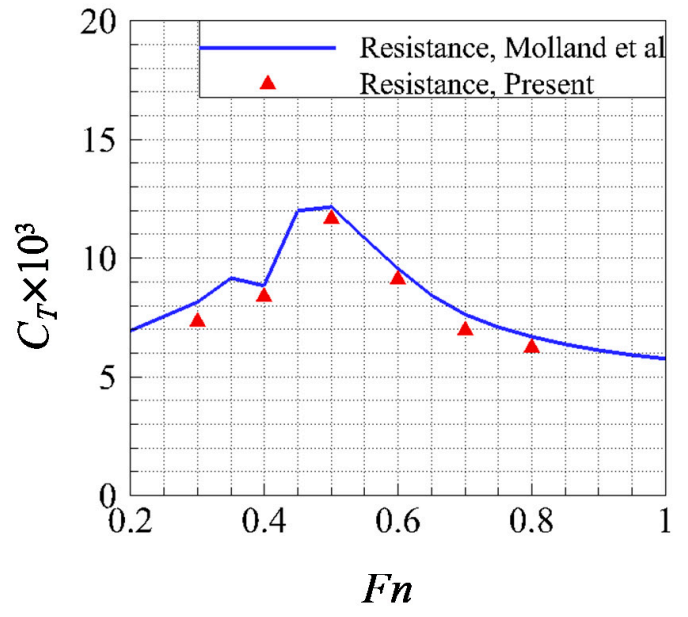

(a)

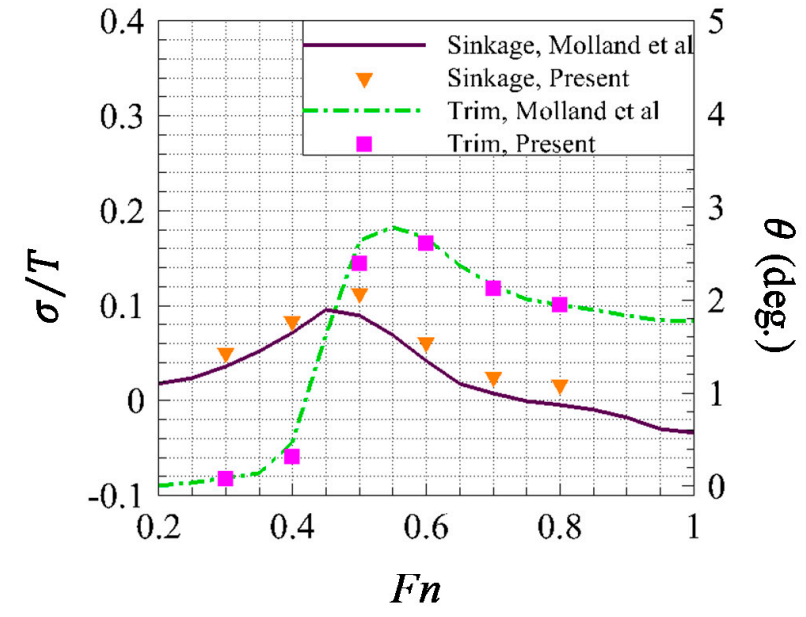

(b)

Figure 5. Total resistance coefficients (a), sinkage and trim (b) of NPL 4a02 model. 


\subsubsection{Stavanger Demonstrator}

The computational methods presented in Section 3 were further validated against the experimental data of the Stavanger demonstrator [2,3] measured in the Hamburg Ship Model Basin (HSVA). The main dimensions are demonstrated in Table 3. The geometry of the Stavanger demonstrator is illustrated in Figure 6a, and the mesh used for simulation is demonstrated in Figure 6b, which was consisted of about 11.4 million cells. The computational domain, boundary conditions and mesh system were generated in similar manners to those presented in Section 3. Table 4 compares the total resistance coefficients of the Stavanger demonstrator obtained from CFD simulations with that from physical model tests. It is seen that for the four speeds considered here, the difference between the present numerical result and the experimental data is within $1.5 \%$.

Table 3. Main dimensions of the Stavanger Demonstrator catamaran.

\begin{tabular}{ccc}
\hline Dimension & Symbol & Value \\
\hline Demihull breadth & $b / L_{p p}$ & 0.074 \\
Separation & $s / L_{p p}$ & 0.227 \\
Draught & $T / L_{p p}$ & 0.045 \\
Vertical centre of gravity & $V C G / L_{p p}$ & 0.016 \\
Longitudinal centre of gravity & $L C G / L_{p p}$ & 0.450 \\
\hline
\end{tabular}

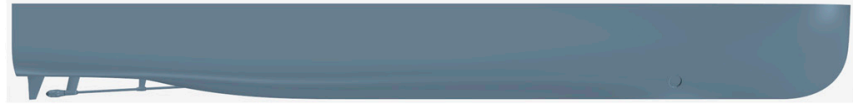

(a)

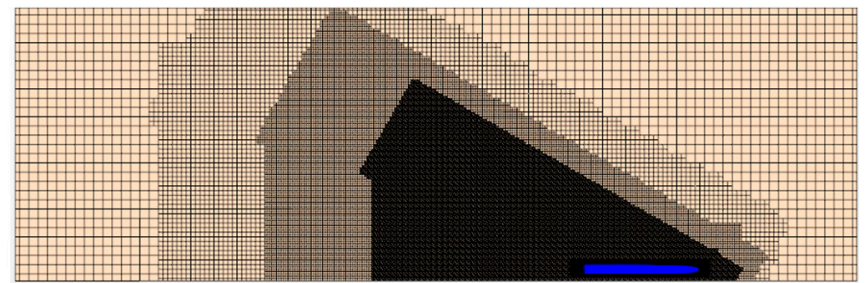

(b)

Figure 6. The geometry of the Stavanger demonstrator (a) and CFD mesh used for simulation (b).

Table 4. Total resistance coefficient of Stavanger demonstrator obtained from model tests and CFD simulation.

\begin{tabular}{cccc}
\hline $\boldsymbol{F n}$ & $\boldsymbol{C}_{\boldsymbol{T}, \boldsymbol{C F D}} \times 10^{3}$ & $\boldsymbol{C}_{\boldsymbol{T}, \text { Exp }} \times 10^{3}$ & Error \\
\hline 0.57 & 5.476 & 5.520 & $-0.79 \%$ \\
0.63 & 4.844 & 4.899 & $-1.11 \%$ \\
0.69 & 4.404 & 4.437 & $-0.74 \%$ \\
0.75 & 4.098 & 4.157 & $-1.42 \%$ \\
\hline
\end{tabular}

\subsubsection{Mesh Convergence Study for the London Demonstrator}

To justify the mesh size used in the simulation of the London Demonstrator and quantify the uncertainties, due to spatial discretisation, a mesh convergence study was carried out. In the present paper, the numerical convergence and uncertainty, due to grid density are evaluated using the grid convergence index (GCI) method described in Stern et al. [50]. The convergence ratio $(\bar{R})$ is used to assess the convergence condition, which is calculated as

$$
\bar{R}=\frac{\varphi_{2}-\varphi_{1}}{\varphi_{3}-\varphi_{2}}
$$

where $\varphi_{1}, \varphi_{2}$ and $\varphi_{3}$ correspond to the solutions (total resistance coefficient) with the fine, medium and coarse grids. Based on the value of $\bar{R}$, the four resulting convergence conditions are: (1) Monotonic convergence $(0<\bar{R}<1)$; (2) oscillatory convergence $(\bar{R}<0$, $|\bar{R}|<1)$; (3) monotonic divergence $(\bar{R}>1)$; and (4) oscillatory divergence $(\bar{R}<0,|\bar{R}|>1)$. 
For convergence conditions, the numerical errors can be predicted as follows. For a constant refinement ratio $\left(\bar{r}=\sqrt[3]{N_{1} / N_{2}}=\sqrt[3]{N_{2} / N_{3}}\right)$, where $N_{1}, N_{2}$ and $N_{3}$ are the number of cells in millions for fine, medium and coarse grids, respectively, the order of accuracy $(q)$ can be calculated as

$$
q=\frac{\ln \left[\left(\varphi_{3}-\varphi_{2}\right) /\left(\varphi_{2}-\varphi_{1}\right)\right]}{\ln (\bar{r})}
$$

The extrapolated values can be obtained by

$$
\varphi_{\text {ext }}^{21}=\frac{\bar{r}^{q} \varphi_{1}-\varphi_{2}}{\bar{r}^{q}-1}
$$

The approximate relative error and the extrapolated relative error can be computed using the following formulas

$$
\begin{gathered}
E_{a, 21}=\left|\frac{\varphi_{1}-\varphi_{2}}{\varphi_{1}}\right| \\
E_{\text {ext }, 21}=\left|\frac{\varphi_{\text {ext }}^{21}-\varphi_{1}}{\varphi_{\text {ext }}^{21}}\right|
\end{gathered}
$$

Finally, the fine-grid convergence index can be predicted as

$$
G C I_{\text {fine }, 21}=\frac{1.25 E_{a, 21}}{\bar{r}^{q}-1}
$$

Table 5 summarises the results for grid convergence study at the design speed $(F n=0.805)$ in shallow water, from which we can observe that the present simulation achieved a monotonic convergence and the uncertainty, due to the spatial discretisation for the fine grid is around $1.5 \%$. As the medium grid is used in the present work, the uncertainty, including the difference between the fine and medium grids, is approximately $2.3 \%$.

Table 5. Results of the mesh convergence study for the London Demonstrator.

\begin{tabular}{ccccccccccc}
\hline $\bar{r}$ & $N_{1}$ & $N_{2}$ & $N_{3}$ & $\varphi_{1}$ & $\varphi_{2}$ & $\varphi_{3}$ & $\bar{R}$ & $E_{a, 21}$ & $E_{\text {ext }, 21}$ & $G_{C I} I_{\text {fine, } 21}$ \\
\hline 1.2 & 10.35 & 5.99 & 3.47 & 2.537 & 2.557 & 2.589 & 0.607 & $0.78 \%$ & $1.22 \%$ & $1.50 \%$ \\
\hline
\end{tabular}

\section{Results and Discussion}

\subsection{Resistance, Sinkage and Trim}

As the present paper aims to validate the numerical methods adopted for simulation, a blind validation study was carried out by MSRC and HSVA, where the commercial solver Star CCM+ 14.06 was used by MSRC, whereas an in-house code FreSCo+ [51] was employed by HSVA. The number of mesh cells for both simulations was approximately 6 million. Figure 7 shows the resistances and motions of the full-scale London Demonstrator in deep water, from which we can observe that very good agreement is accomplished between the present results (Strath) and those from HSVA. It is seen from Figure 7a that the total resistance $\left(R_{T}\right)$ rises monotonously as the speed of the catamaran increases. The relation between $R_{T}$ and $F n$ is almost linear when $F n<0.4$. A continuous change in the slope of the total resistance curve can be observed when $0.4<F n<0.6$, which is also reported by Zaghi et al. [30] in the same Froude number range and indicates the experience of unfavourable interferences. The frictional component $\left(R_{F}\right)$ also rises monotonously with increased speed, while the pressure component $\left(R_{P}\right)$ experiences a peak of $F n=0.575$. Besides, $R_{P}$ is the larger component at lower speeds whilst it becomes smaller when $F n$ is greater than 0.65. 


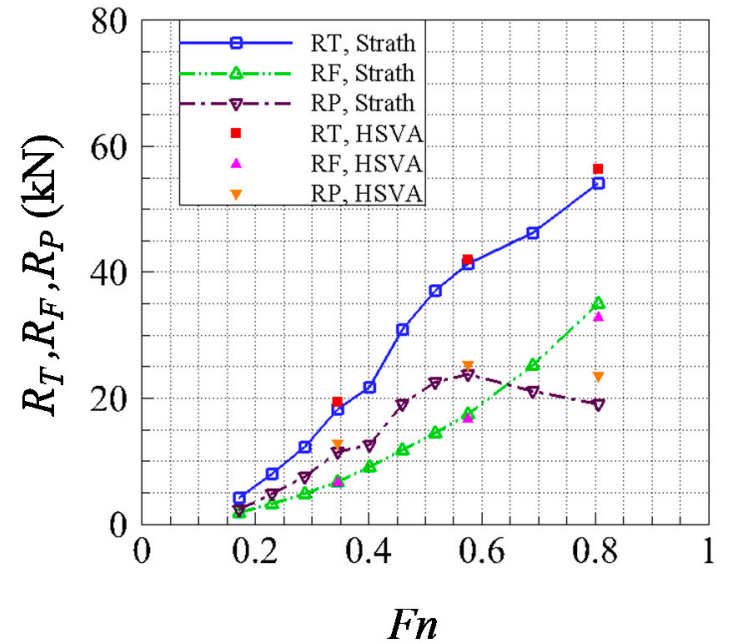

(a)

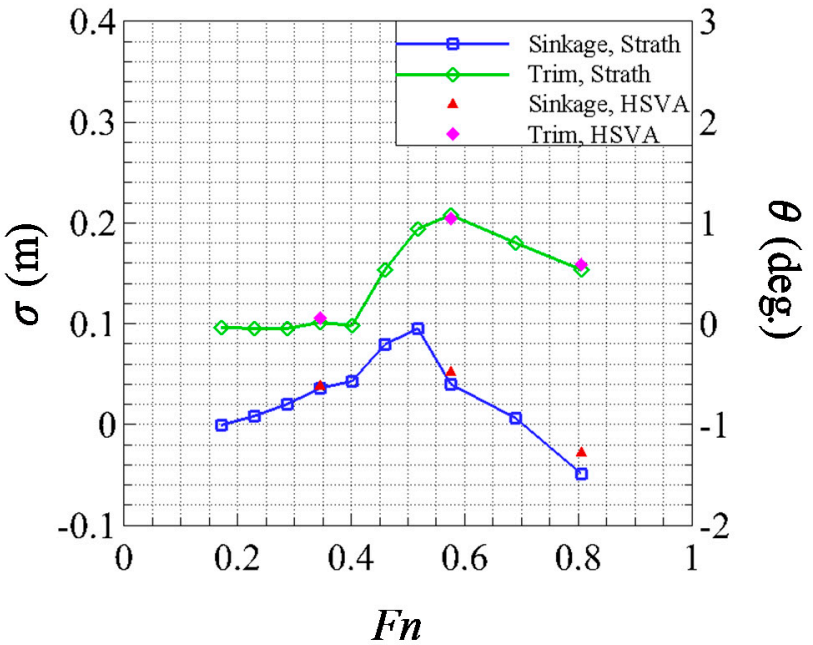

(b)

Figure 7. Resistances (a) and motions (b) of the London Demonstrator in deep water.

The sinkage and trim are demonstrated in Figure $7 \mathrm{~b}$, and it is observed that the trim angle of the catamaran is always positive, i.e., the stern goes down for all speeds considered here. At lower speeds $(F n<0.4)$, the trim angle of the London Demonstrator remains almost zero. When $F n$ becomes higher than 0.4 , it rises significantly and reaches its peak of $F n=0.575$ where $R_{P}$ also achieves its maximum value. In terms of the sinkage of the catamaran, it keeps positive (the hull moves downwards) until the $F n$ is higher than 0.7 . The largest sinkage is experienced at $F n=0.517$, which is slightly smaller than the Froude number where the trim maximum is accomplished. It should also be noted that the significant changes in trim and sinkage occur when $0.4<F n<0.6$, corresponding to the range where the total resistance curve varies. It will be shown in the following sections that these behaviours of resistance and motion are closely associated with the position and strength of the crests and troughs at the central plane of the catamaran.

Figure 8 compares the resistances and motions of the London Demonstrator in shallow water obtained from the present calculation with those computed by HSVA using FreSCo+. The results from both solvers also agree very well with each other for shallow water scenarios. It is interesting to observe from Figure $8 \mathrm{a}$ that $R_{T}$ experiences a hump at $F n=0.287$, corresponding to a depth Froude number $\left(F n_{H}=1.12\right)$ around the critical value. It has been widely acknowledged that fast catamarans will experience a dramatic surge in total resistance coefficient near the critical speed in shallow water [45,48]. However, the existence of such a hump in total resistance rather than the coefficient near the critical depth Froude number is rarely reported in previous studies. $R_{T}$ rises monotonously after the hump (when $F n>0.35$ ) as the continuous increase of the frictional resistance. An inspection of $R_{P}$ and $R_{F}$ curves reveal that the hump comes from the pressure component of the resistance, indicating it is the consequence of wave interference between the demihulls. Unlike the total resistance, $R_{P}$ declines after the hump and the frictional resistance exceeds $R_{P}$ and becomes the larger part of the total resistance when $F n>0.55$. The existence of such a hump in the $R_{T}$ curve should be carefully considered in the design of the catamaran to guarantee that the installed power is sufficient to overcome the hump resistance in the process of accelerating the vessel to the designed speed. It is observed from Figure $8 \mathrm{~b}$ that the sinkage and motion of the catamaran change significantly near the critical speed, which agrees with previous studies on high speed catamarans [45,48]. 


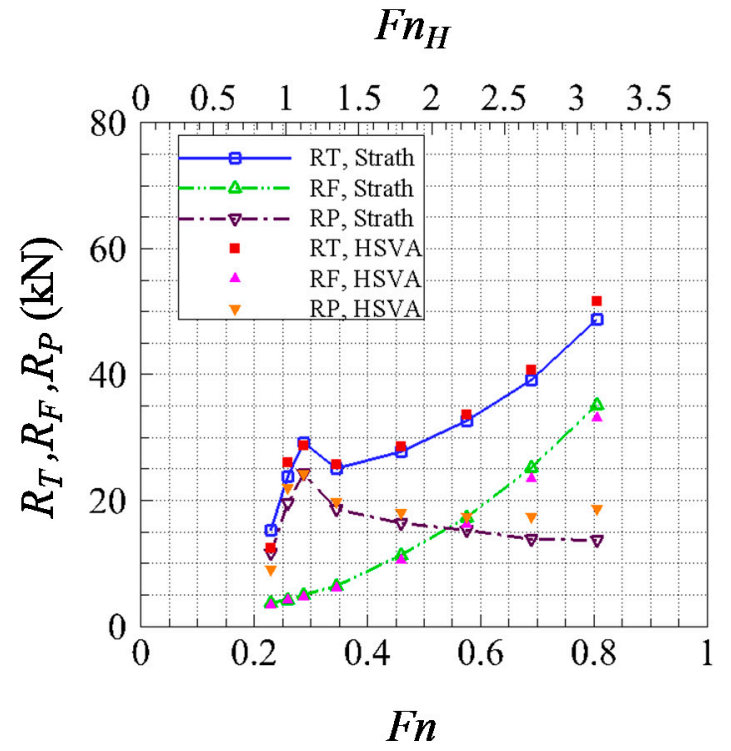

(a)

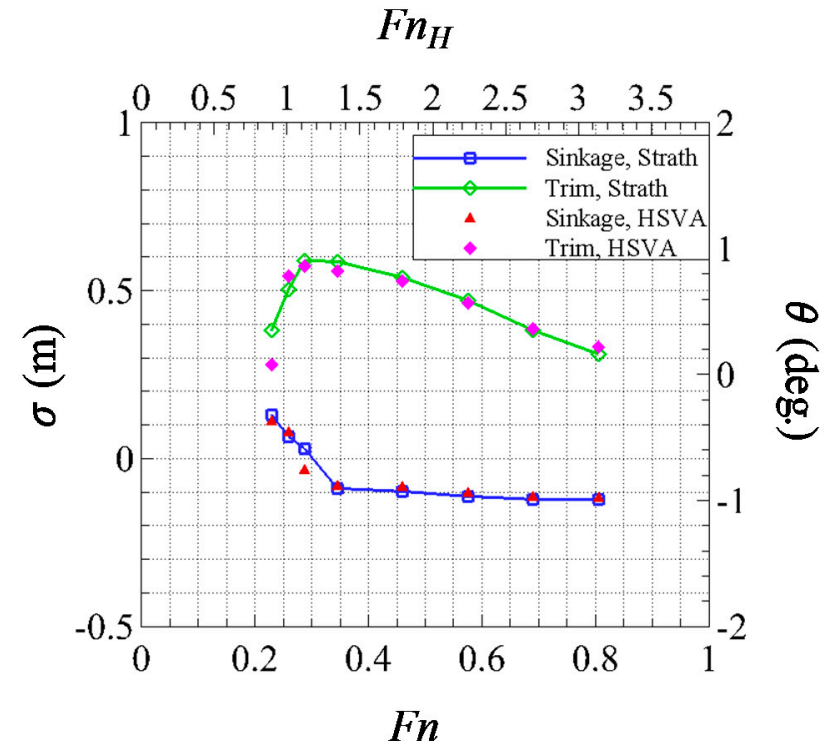

(b)

Figure 8. Resistances (a) and motions (b) of the London Demonstrator in shallow water $(H=2.15 \mathrm{~m})$.

Figure 9 compares the resistances and motions of the London Demonstrator in deep and shallow water. Hereafter, only the results computed using Star CCM+14.06 are used for further analysis. The total resistance in shallow water is higher than that in deep water at smaller Froude numbers $(F n<0.45)$ because of the hump near the critical speed. When $F n$ further increases, $R_{T}$ in shallow water becomes lower, due to the reduction of pressure resistance $R_{P}$. The frictional resistances in deep and shallow water are almost the same, i.e., the difference between the total resistance in deep and shallow water results from significantly different wave patterns and interferences, which will be demonstrated in the following sections. By comparing the motions of deep and shallow water cases, it is found that the maximum trim angles accomplished in deep and shallow water are close to each other $(\approx 1.0$ degree). However, the maximum of trim in shallow water is reached near the critical speed $(F n=0.287)$, whereas the peak in deep water is achieved at $F n=0.575$. Similar to deep water cases, the maximum value of shallow water trim is also achieved at the Froude number where the pressure resistance peaks $(F n=0.287)$. The sinkage of the catamaran in shallow water is larger in sub- and trans-critical ranges $(F n<0.3)$, whilst in the supercritical region, the sinkage in shallow water becomes smaller than that in deep water, which leads to a considerable reduction in pressure drag, as observed from Figure 9a. Furthermore, the sinkage of the catamaran in shallow water is positive at subcritical speeds. With the further increase of Froude number, the catamaran's centre of mass starts to move upward and when $F n>0.35$, the change rate of sinkage becomes less significant.

The resistance coefficients of the London Demonstrator in deep and shallow water are illustrated in Figures 10 and 11, respectively. The total resistance coefficients $\left(C_{T}\right)$ are normalised using both static and dynamic areas and the differences are small for both deep and shallow water cases. Generally, the coefficients calculated based on the dynamic wetted area are slightly smaller, and the difference only becomes noticeable for the highest speed $(F n \approx 0.8)$. The frictional resistance coefficients $\left(C_{F}\right)$ of the catamaran in both deep and shallow water agree well with those predicted using the ITTC 1957 correlation line formula, indicating the frictional resistance is not significantly affected by shallow water. Moreover, for deep water cases, shown in Figure $10, C_{T}$ and $C_{P}$ experience multiple peaks as the increase of Froude number. The peaks at lower Froude numbers $(F n<0.4)$ are higher than that at $F n=0.46$. The total resistance coefficient drops significantly with the further increase of the advance speed. The present $C_{T}$ curve differs from those observed in some previous studies, where the humps at smaller Froude numbers were usually lower $[9,13,30]$. 
This may be associated with the exact hull form and configuration of the catamaran, which leads to a different wave interference between the demihulls.

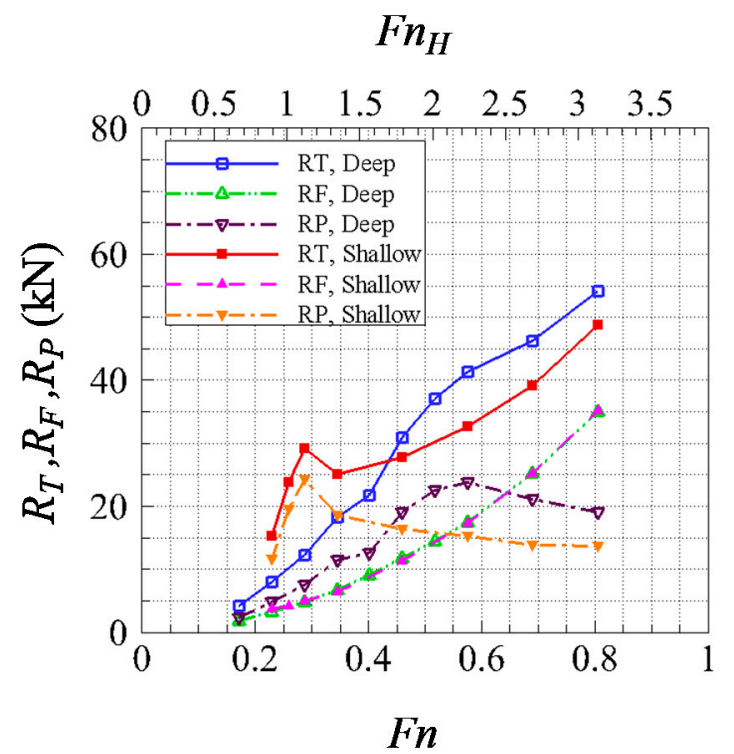

(a)

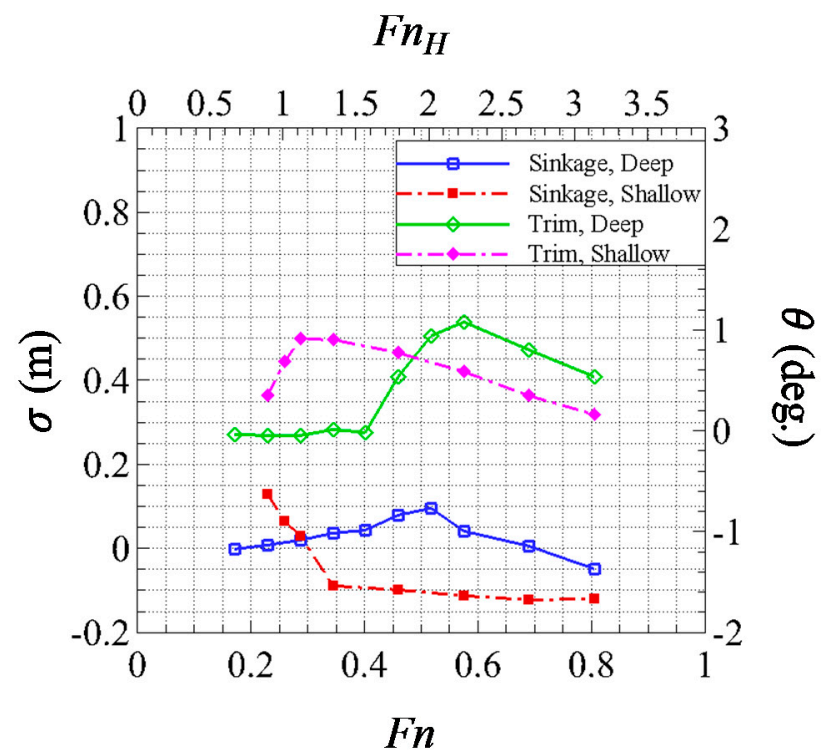

(b)

Figure 9. Comparison of resistances (a) and motions (b) of London Demonstrator in deep and shallow water $(H=2.15 \mathrm{~m})$.

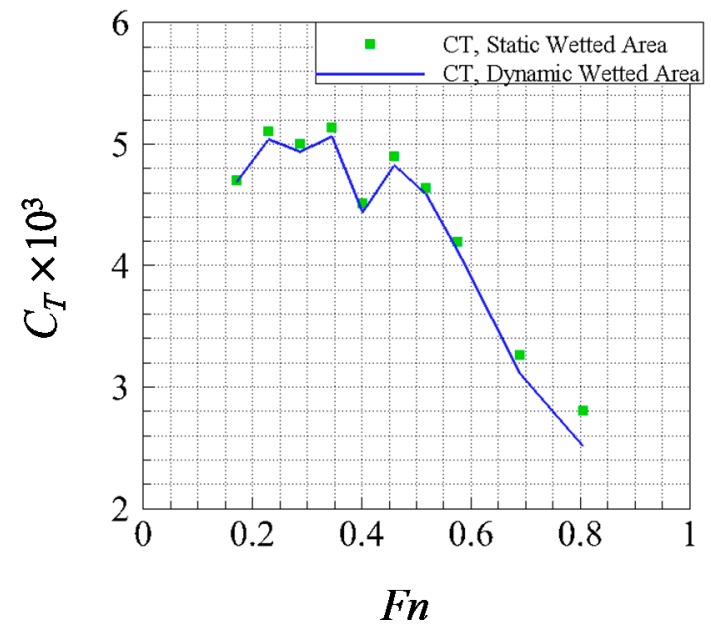

(a)

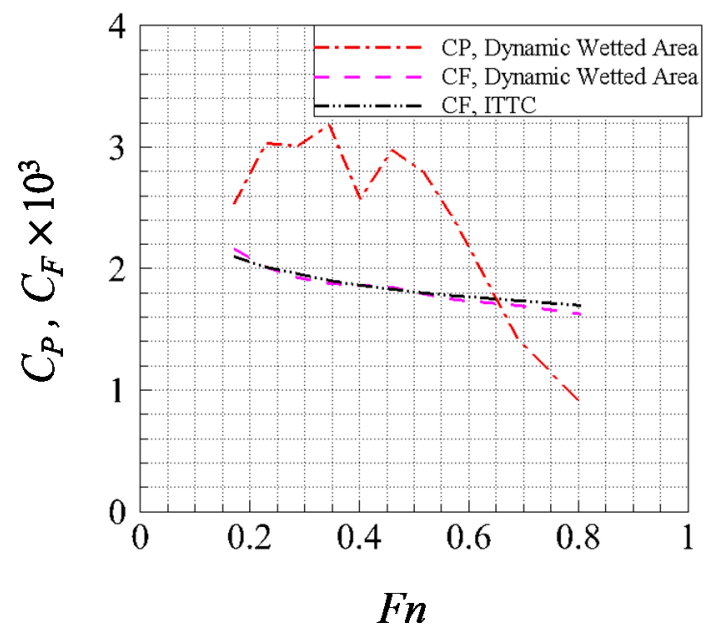

(b)

Figure 10. Total resistance coefficient (a), and pressure and frictional resistance coefficients (b) of the London Demonstrator in deep water.

For the shallow water scenario (Figure 11), the resistance coefficient of the catamaran reaches its peak value around the critical depth Froude number and then declines dramatically as the moving speed increases. The maximum $C_{T}$ value in shallow water is approximately 2.4 times higher than that created in deep water. This ratio is smaller than the value obtained by Castiglione et al. [48] for a similar catamaran configuration, where the $C_{T}$ peak in shallow water is about 4.2 times larger than that in deep water. Unlike the hump of the $R_{T}$ curve in shallow water, as shown in Figure 9a, which is not commonly seen in previous papers, the dramatic increase of $C_{T}$ near the critical speed has been widely observed in both model tests and numerical simulations $[45,48]$. It is worth noting that the maximum total resistance coefficient does not correspond to the maxima of the total resistance, according to which the propulsion power should be installed. For the London 
Demonstrator examined here, the maximum total resistance is accomplished at the highest speed considered here (see Figure $9 \mathrm{a}$ ), where $C_{T}$ reaches its minimum value.

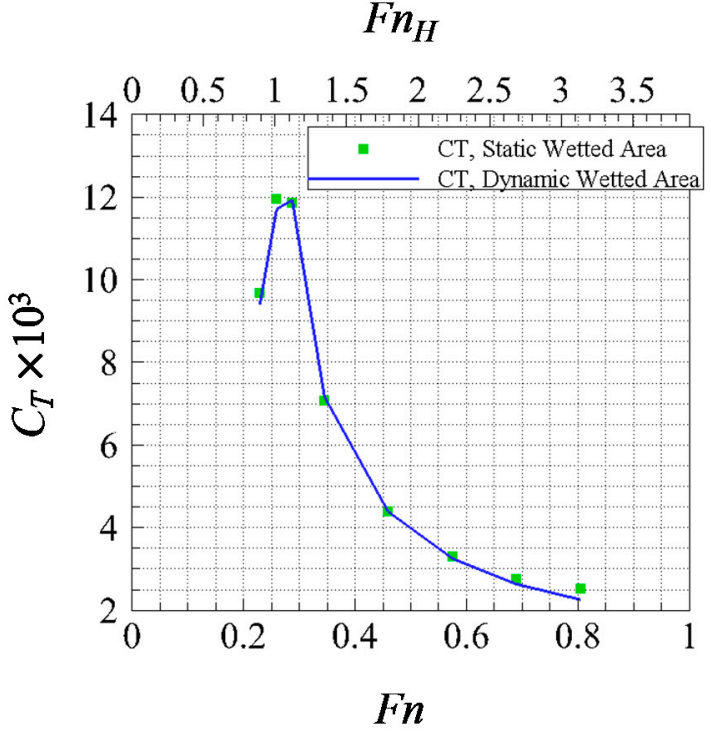

(a)

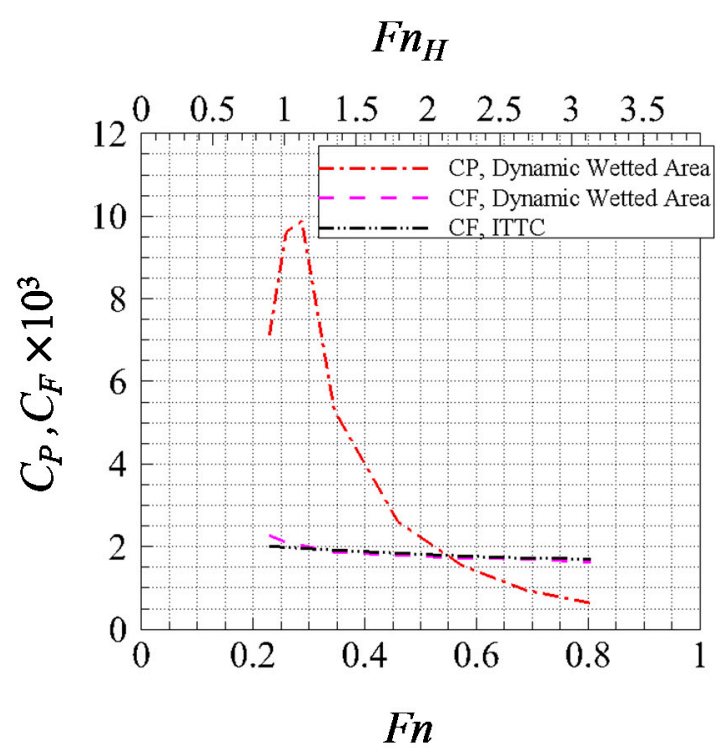

(b)

Figure 11. Total resistance coefficient (a), and pressure and frictional resistance coefficients $(\mathbf{b})$ of the London Demonstrator in shallow water.

\subsection{Wave Patterns}

The wave patterns created by the London Demonstrator at various speeds in deep water are demonstrated in Figure 12. The catamaran generates typical Kelvin wave patterns at lower speeds, which comprise both transverse and divergent waves. As the increase of the Froude number, the amplitude and length of the induced wave also increase, while the Kelvin wave angle becomes smaller. Besides, the divergent waves become dominant in the wave pattern at $F n=0.805$. Figure 13 demonstrates the wave elevations of the catamaran in shallow water, which are profoundly different from those shown in Figure 12. As expected, when the depth Froude number is near its critical value $\left(F n_{H}=1.0\right)$, the Kelvin wave angle is close to 90 degrees, and the critical wave is created at $F n_{H}=1.12$, which is located right in front of the catamaran. The critical wave is normal to the advance direction of the vessel, and its attitude is significantly elevated, which leads to the hump observed in the $R_{T}$ curve in Figure 8a and the remarkable $C_{T}$ peak, shown in Figure 11b. Besides, the critical wave significantly elevates the bow, creating the trim maxima observed from Figure 8b. Behind the stern of the vessel, divergent waves are generated. As the moving speed increases to the supercritical range, the critical wave disappears, and divergent waves are created near both the bow and stern of the hull. The further increase of the Froude number reduces the angles of the divergent waves. However, the overall wave patterns are not significantly changed. In both deep and shallow water, the decrease of the Kelvin wave angle leads the intersection point of the bow waves created by the two demihulls to move astern, which will be more clearly observed from Figures 14 and 15, as well as the wave cuts demonstrated in the next section. 

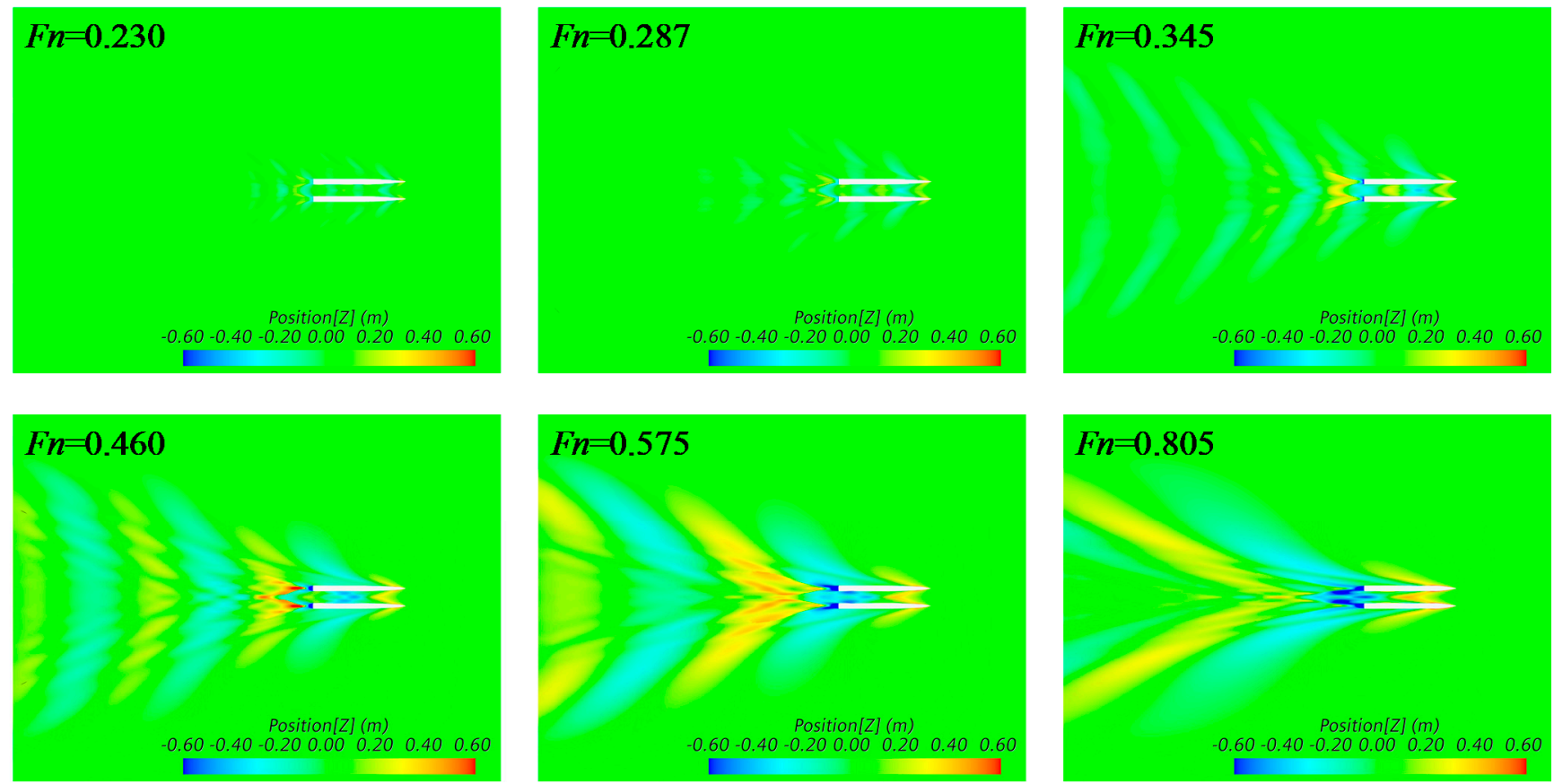

Figure 12. Wave patterns created by the London Demonstrator in deep water.
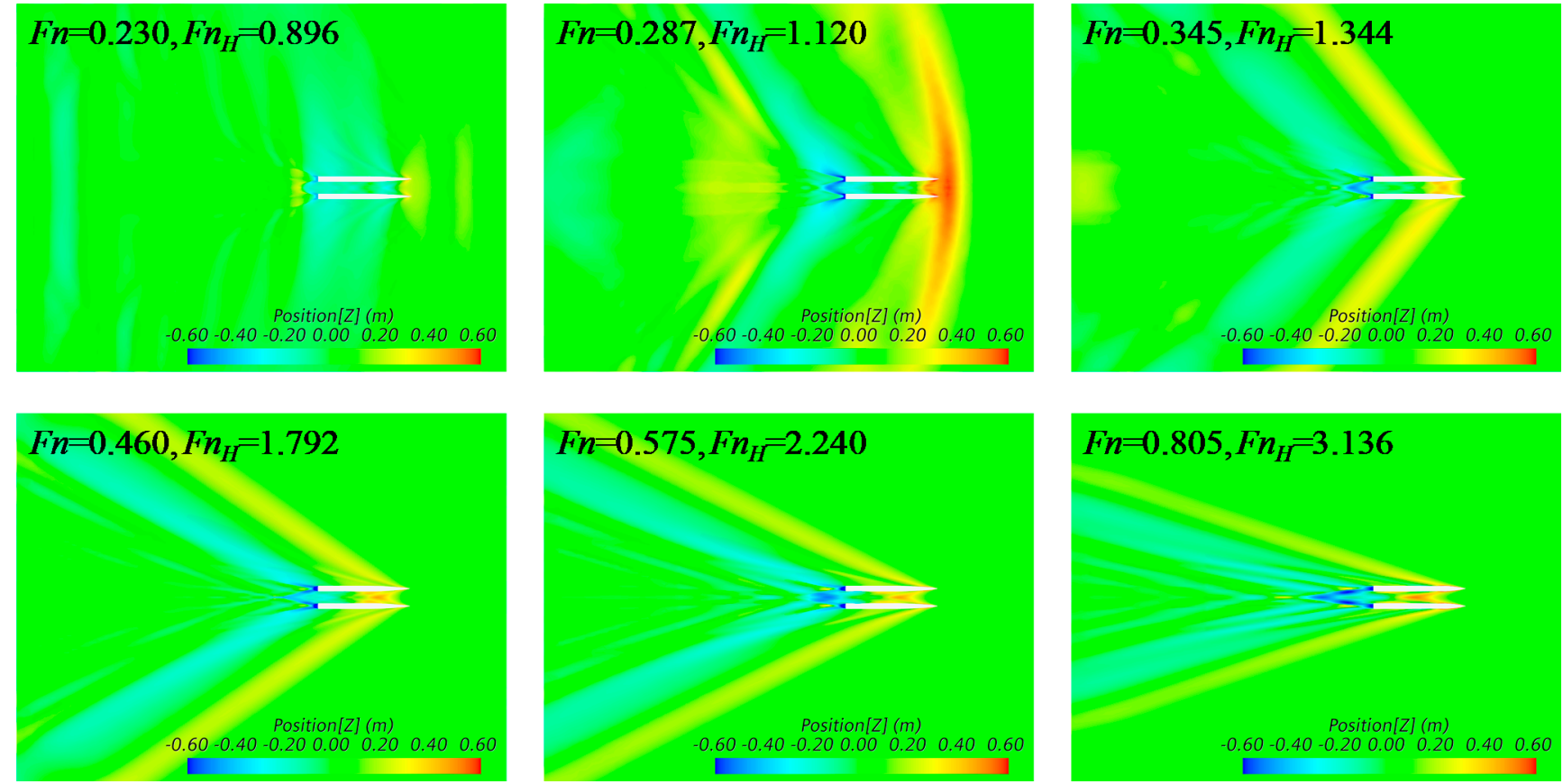

Figure 13. Wave patterns created by the London Demonstrator in shallow water.

The behaviours of the resistance, trim and sinkage discussed in the previous section can be better understood by analysing the interaction between the wave systems generated by the demihulls. Figure 14 shows a closer inspection of the wave interference between the demihulls in deep water. We can observe that at smaller Froude numbers (e.g., when $F n<0.3)$, multiple crests and troughs exist within the inner region between the two hulls. Enhanced crests and troughs become pronounced when $F n=0.345$ at the symmetry plane of the catamaran, where the waves meet and strengthen each other. At $F n=0.46$, another two troughs are generated on each side of the symmetry plane apart from the one created at the central plane, indicating a significant secondary wave interference. At this 
Froude number, the secondary troughs are located slightly behind midship. As the Froude number increases to 0.575 , the crest and troughs between the demihulls are moved further downstream, which has also been reported in previous studies [13,30]. In particular, the secondary wave troughs are generated near the stern with higher amplitudes, which leads to a larger sinkage at the stern, thereby creating the peak of trim, as shown in Figure $7 \mathrm{~b}$. Moreover, as discussed in Figure 9a, the pressure resistance $R_{P}$ reaches its maximum value at $F n=0.575$, implying the wave interference is the strongest at this Froude number. When $F n=0.805$, the wave troughs created, due to the secondary wave interaction are moved behind the aft of the catamaran (see Figure 12), which leads to a decrease in the trim as the secondary troughs are closer to the hull surface, thereby having a more direct impact on the motion of the demihull. Another observation from the wave pattern at $F n=0.805$ is that the first crest in the inner region is produced near midship, which results in the reduction of the moment causing the pitch motion, leading to the decrease in trim angle. On the other hand, with the first crest further strengthened and moved near the catamaran's centre of mass, this crest will lift the entire catamaran instead of the bow. Therefore, the sinkage becomes negative (the hull moves upward) at higher Froude numbers.
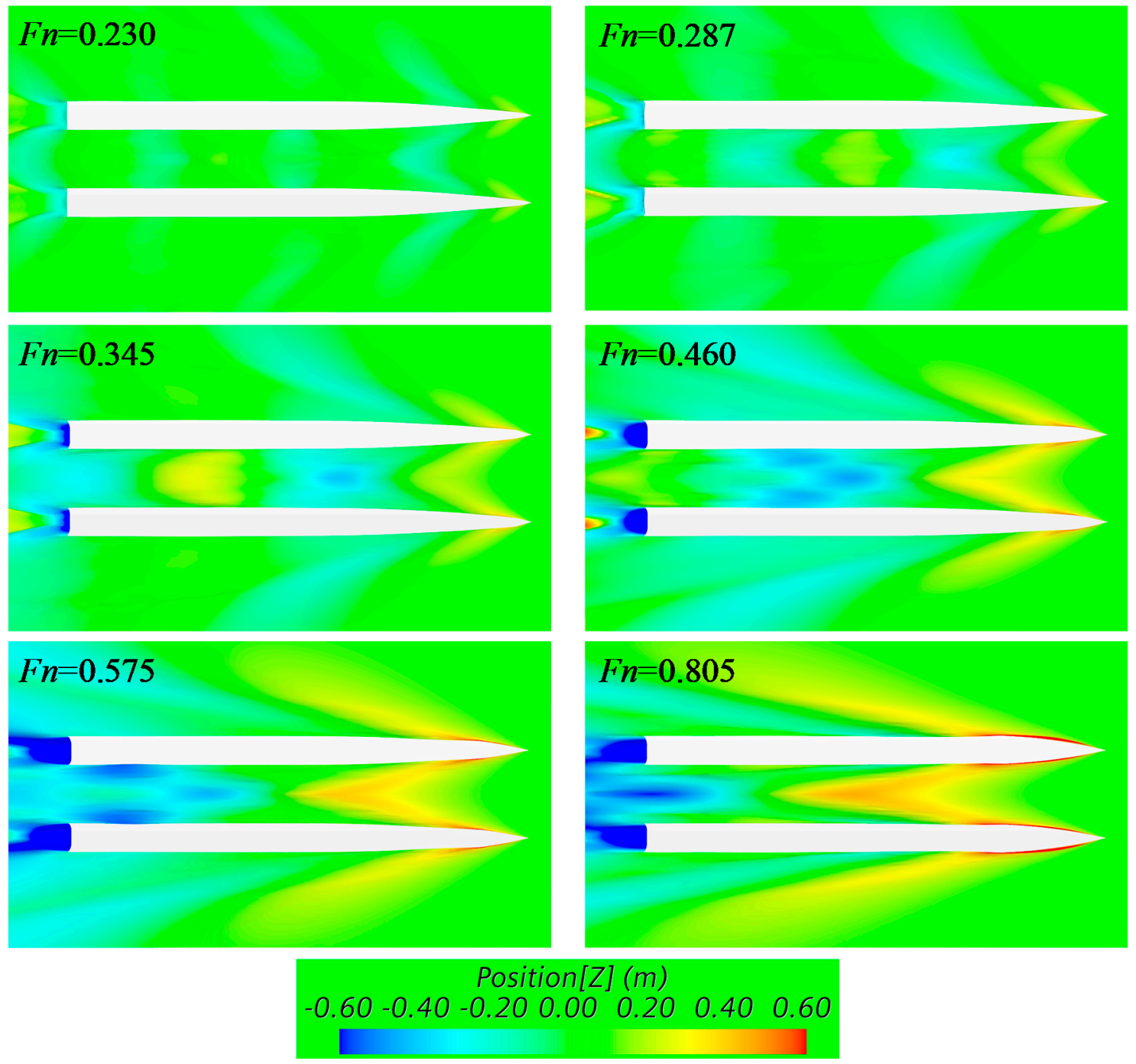

Figure 14. The wave interaction between demihulls in deep water. 

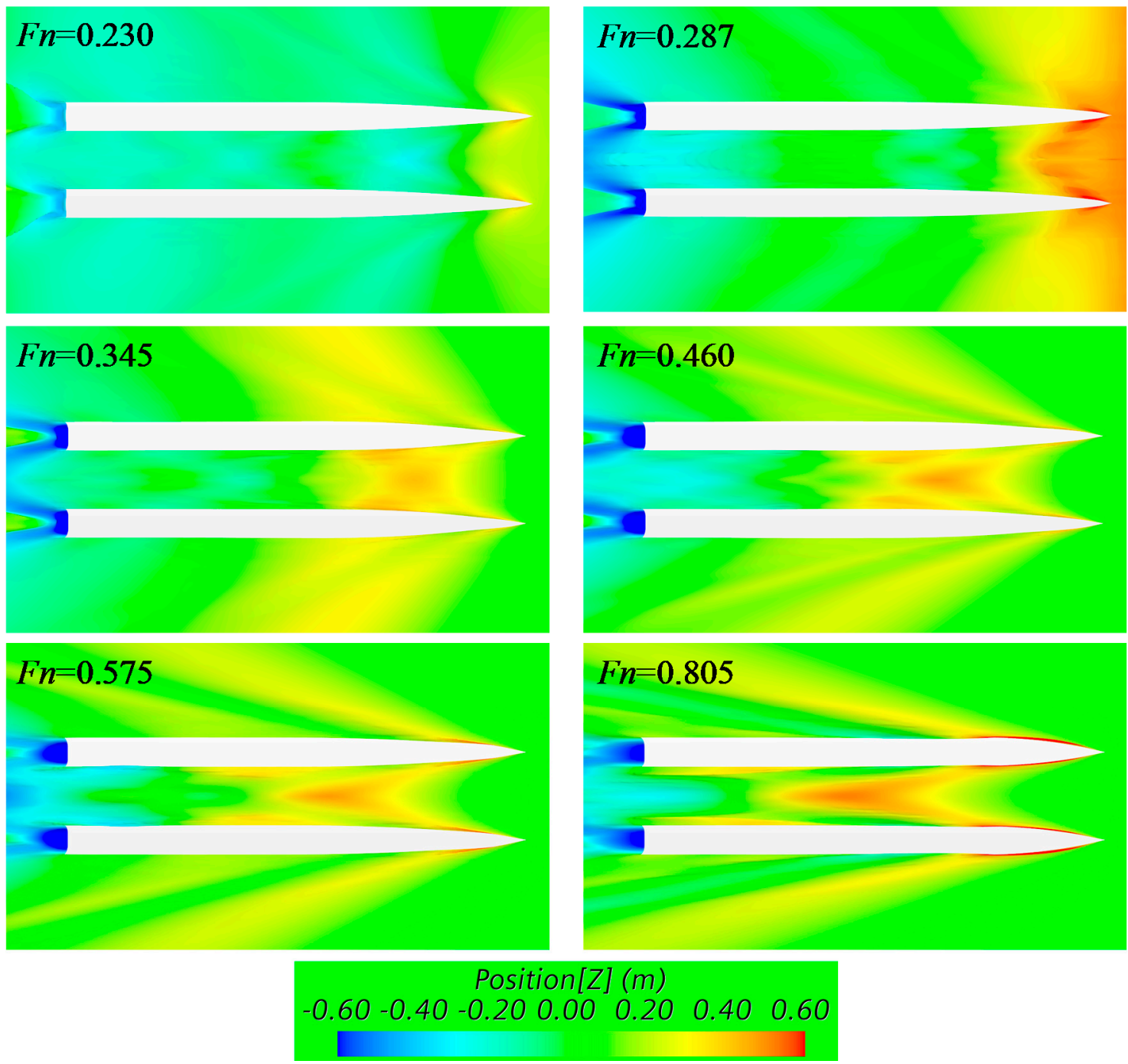

Figure 15. The wave interaction between demihulls in shallow water.

The wave interferences between demihulls in shallow water are demonstrated in Figure 15. Several significant differences from those in deep water can be observed. First, at trans-critical speeds $(F n=0.23$ and 0.287$)$, wave interactions between the demihulls seem to be suppressed, due to creating the critical wave in front of the catamaran (see Figure 13), i.e., the phenomenon of existing multiple crests and troughs within the inner region disappears. At supercritical speeds $(F n>0.345)$, the three troughs observed in deep water (e.g., in Figure 14 when $F n=0.46$ ) are not seen in shallow water cases. Instead, another two secondary crests are generated apart from the primary one at the catamaran's central plane. As the Froude number increases, the wave crests are stretched and moved towards the stern. As previously discussed, both trim and sinkage will be decreased with the first crest moving midship. This trend will be further enhanced, due to creating the secondary crests, i.e., at higher speeds, both the trim and sinkage in shallow water are smaller, as seen from Figure $9 b$.

\subsection{Longitudinal Wave Cuts}

The wave propagation within the inner region can be better understood by analysing the longitudinal wave cuts at the central plane of the catamaran, as demonstrated in Figure 16. It is seen that the wave starts to come into being at the forward perpendicular (FP) for all cases except those at trans-critical speeds $\left(F n_{H}=0.896\right.$ and 1.12) in shallow water, where the water is elevated at least $0.5 L_{p p}$ ahead of the catamaran and reaches 
the maximum height near the FP. In deep water, both the wave height and wave length increase as the Froude number rises, confirming the observations from Figure 14. The increase of the wave length leads to a reduction in the number of waves between FP and aft perpendicular (AP). For example, there are approximately three waves between FP and AP when $F n=0.23$, while the number becomes less than one when $F n$ increases to 0.805. It is interesting to observe that at $F n=0.575$, the wave number between FP and $\mathrm{AP}$ is approximately unity and this Froude number corresponds to the maximum value of the pressure component of total resistance (see Figure 9a). In shallow water, the first wave crest behind the bow is always higher than that created in deep water, especially near the critical speed. The difference is considered small only when the Froude number is greater than 0.575 . Moreover, no noteworthy wave troughs are generated between FP and AP in shallow water, which significantly differs from those in deep water. Furthermore, the catamaran generates higher wave crests behind the stern in deep water, while creating deeper wave troughs in shallow water.
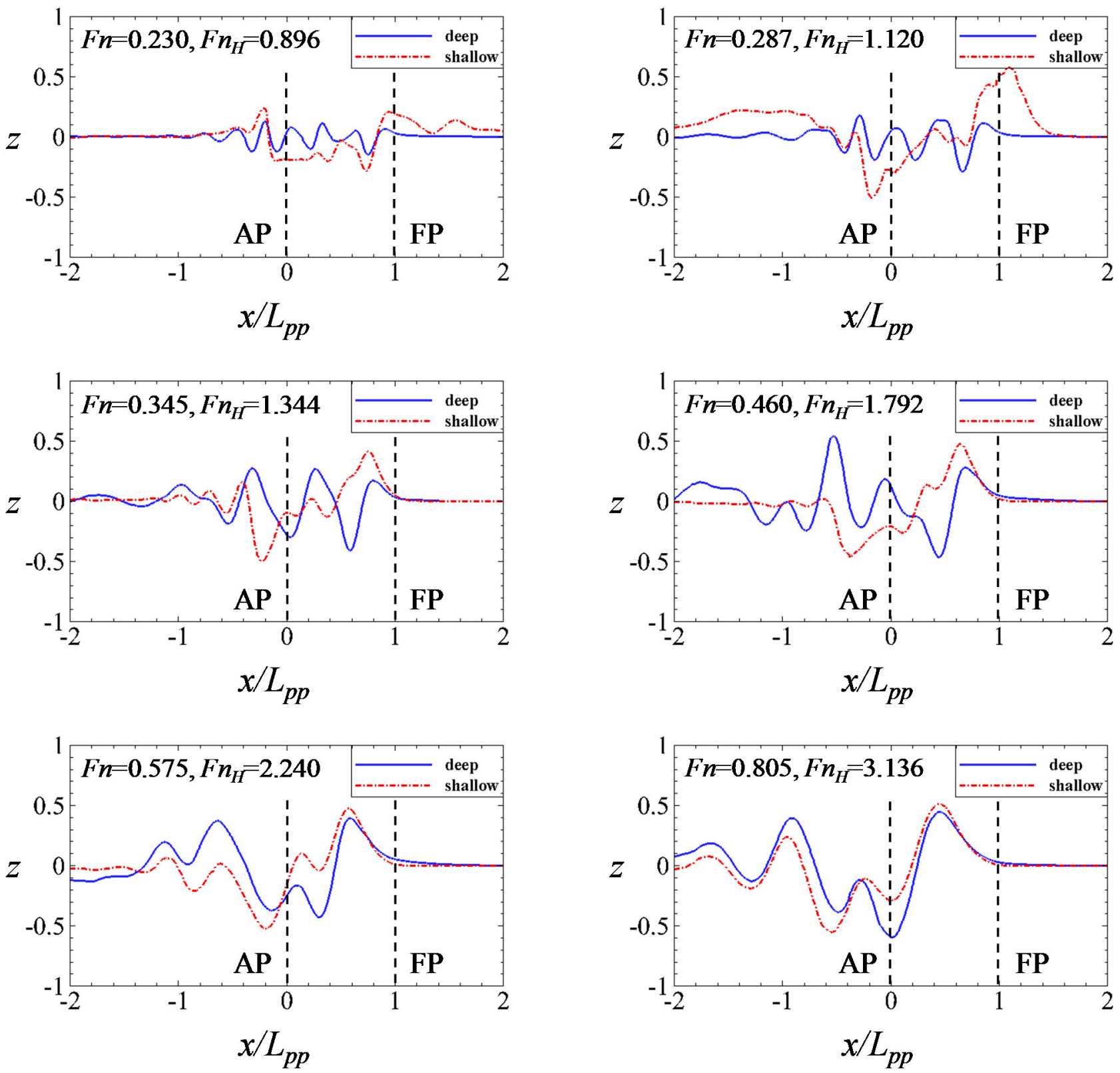

Figure 16. Comparison of the longitudinal wave cuts at the catamaran symmetry plane in deep and shallow water. 
As observed from previous wave patterns in Figures 14 and 15, the catamaran generates a remarkable trough right behind the stern of the demihull. The magnitude of this trough can be more clearly demonstrated by the longitudinal wave cuts at the mid-plane of the demihull, as shown in Figure 17. In deep water, the magnitude of the trough reaches its maximum value at $F n=0.575$, where the water level difference between FP and AP is also maximised. In shallow water, the trough's magnitudes at trans-critical speeds are significantly larger than those in deep water. The maximum amplitude is achieved at $F n=0.287$, where the critical wave is also created in front of the bow, resulting in a remarkably large difference between the water levels at the FP and AF of the catamaran. It is worth emphasising that $F n=0.287$ and 0.575 correspond to the speeds where the maximum pressure resistance is produced in shallow and deep water, respectively, as seen from Figure 9a. At supercritical speeds, the trough's amplitude in shallow water becomes smaller than that in deep water, which can be attributed to smaller sinkage and trim created in shallow water.
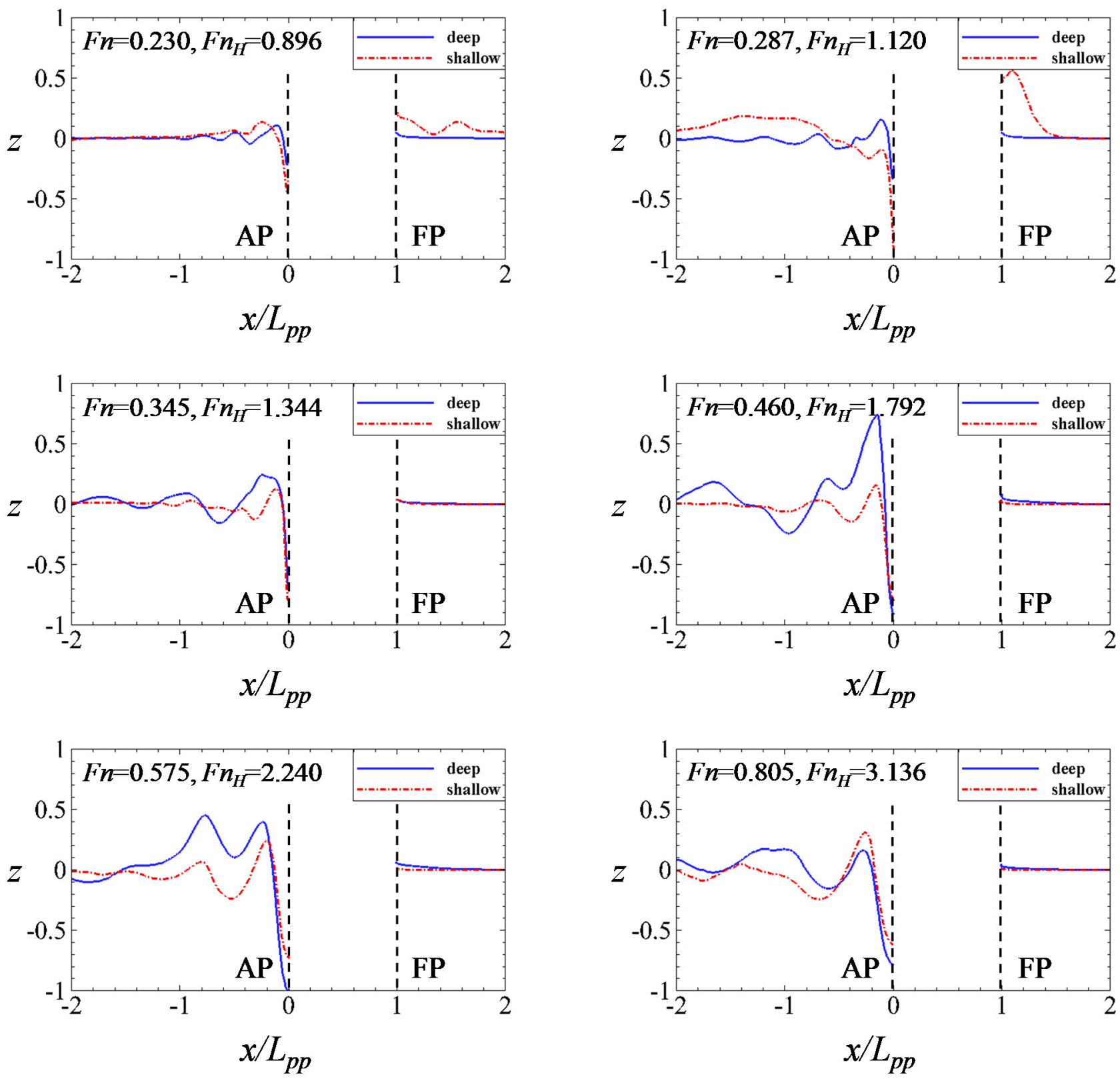

Figure 17. Comparison of the longitudinal wave cuts at the mid-plane of the demihull in deep and shallow water. 


\subsection{Crossflow Fields}

With the wave interference between the demihulls, the flow field created by the demihull becomes non-symmetrical against its mid-plane, which will cause a transverse pressure gradient. This can further lead to a crossflow under the keel of the demihull, which is believed to be one of the main causes of the increase in total resistance [31]. The crossflow fields of the London Demonstrator are plotted in Figure 18, where the positive and negative velocities indicate that the flow moves to the outer and inner regions, respectively. In deep water, the location and strength of the crossflow are closely associated with the wave interaction between the demihulls. At lower Froude numbers, multiple changes of the crossflow direction under the keel can be observed, which corresponds to the existence of multiple waves between the demihulls (see Figures 14 and 16). With the increase of the Froude number, the strength and extension of the crossflow are significantly enhanced, and the locations where the crossflow occurs is also moved towards the stern. This phenomenon was also observed by Zaghi et al. [30] and Farkas et al. [34]. Besides, the number of changes in the crossflow direction is also reduced with increased speed. At higher Froude numbers, significant crossflows are also generated behind the stern. For shallow water scenarios, similar to the deep water cases, the strength of the crossflow is considerably enhanced and the location where the maximum crossflow occurs is also moved towards the stern with increased speed. However, the crossflows created in shallow water are remarkably stronger than the corresponding cases in deep water. Moreover, the phenomenon of multiple changes in crossflow direction observed at lower Froude numbers no longer exists, and for all speeds in shallow water, the crossflow moves from the inner side of the demihull to the outer region.

Deep water

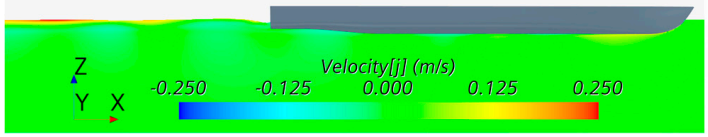

$F n=0.230$

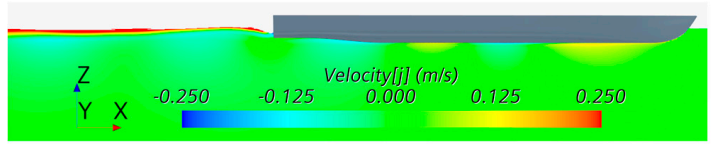

$F n=0.287$

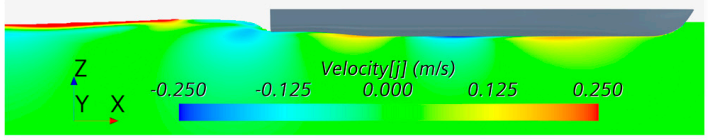

$F_{n}=0.345$

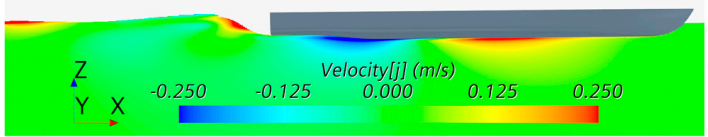

$F n=0.460$

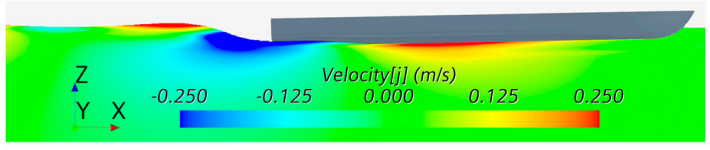

$F n=0.575$

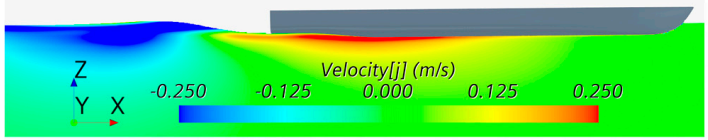

$F n=0.805$
Shallow water

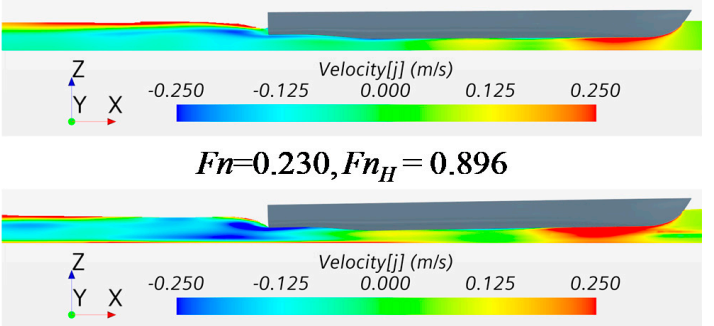

$F n=0.287, F n_{H}=1.120$

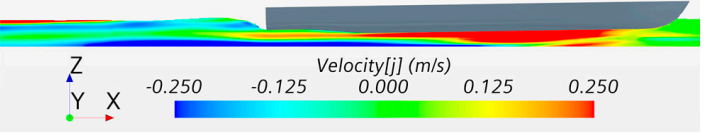

$F n=0.345, F n_{H}=1.344$

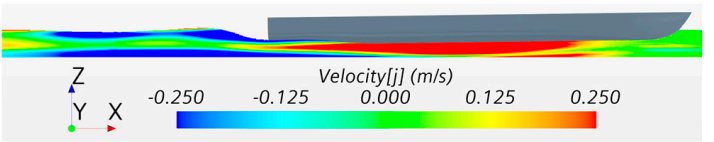

$F n=0.460, F n_{H}=1.792$

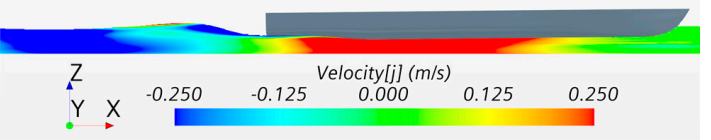

$F n=0.575, F n_{H}=2.240$

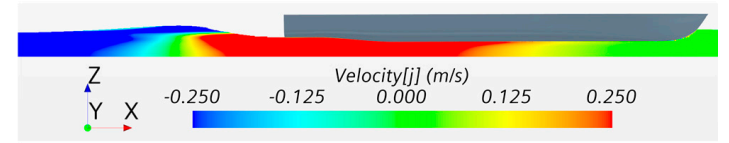

$F n=0.805, F n_{H}=3.136$

Figure 18. Crossflow fields at the mid-plane of the demihull for deep (left) and shallow (right) water. Positive and negative velocity values mean the flow moves towards the outer and inner sides of the demihull, respectively. 


\section{Conclusions}

In the present work, the hydrodynamics of a full scale, zero-emission, high-speed catamaran (London demonstrator) in both deep and shallow water was numerically investigated. The numerical methods used in the current study were validated against experimental data of the NPL $4 \mathrm{a} 02$ model [9] and the Stavanger demonstrator [2]. For numerical simulations on the London Demonstrator, a blind validation was also carried out in collaboration with HSVA and good agreement was accomplished.

The resistance, sinkage and trim of the London Demonstrator as functions of Froude number (ranged from 0.2 to 0.8 ) in deep and shallow water were firstly analysed. The total resistance in deep water increased continuously, while in shallow water, a hump was experienced at $F n=0.287\left(F n_{H}=1.12\right)$. Besides, the total resistance in shallow water was higher when $F n<0.45$ and became smaller at larger speeds. As the frictional resistance was almost the same in deep and shallow water, i.e., the difference in total resistance was mainly caused by the pressure component. The variations of the pressure resistance were closely related to the behaviours of trim and sinkage. In particular, the maximum trim was accomplished at the Froude number where the pressure resistance was maximised ( $F n=0.287$ and 0.575 for shallow and deep water, respectively). The largest sinkage in shallow water occurred at the lowest speed, whereas in deep water the sinkage reaches its maxima at a Froude number $(F n=0.517)$ slightly lower than the one where the maximum trim occurred. Furthermore, the total resistance coefficient curve in deep water showed multiple humps, while only one significant peak near the critical speed was produced in shallow water.

The computed wave patterns, longitudinal wave cuts and crossflow fields were also analysed and correlated with the behaviours of the resistance and motion of the catamaran. In general, for both deep and shallow water scenarios, the crests and troughs generated within the inner region were strengthened and moved astern with the increase of Froude number. In deep water, the maximum pressure resistance was related to creating a secondary trough near the stern of the demihull. In contrast, the mechanism involved in shallow water was due to the generation of a critical wave in front of the catamaran and normal to the moving direction. Moreover, the creation of maximum pressure resistance was also correlated with the largest water level difference between the forward and aft perpendiculars. Crossflows occurred in deep and shallow water scenarios, due to the asymmetrical flow fields between the inner and outer regions. Compared with deep water cases, the crossflows created in shallow water were much stronger. Moreover, the crossflow in shallow water moved towards the outer region for all speeds considered here, whereas, in deep water, changes in crossflow directions were observed.

Author Contributions: Conceptualization, E.B.; methodology, G.S. (Guangyu Shi), A.P. and Y.X.K.; software, G.S. (Guangyu Shi), A.P. and Y.X.-K.; validation, G.S. (Guangyu Shi), Y.X.-K.; formal analysis, G.S. (Guangyu Shi); investigation, G.S. (Guangyu Shi), A.P., E.B., Y.X.-K. and A.D.P.; resources, E.B.; data curation, G.S. (Guangyu Shi); writing-original draft preparation, G.S. (Guangyu Shi); writing-review and editing, E.B., A.P., H.W. and A.D.P.; visualization, G.S. (Guangyu Shi); supervision, E.B.; project administration, E.B., G.S. (Geoff Symonds); funding acquisition, E.B.. All authors have read and agreed to the published version of the manuscript.

Funding: This research was funded by European Commission (EC), grant number 769303.

Data Availability Statement: Not applicable.

Acknowledgments: This work was funded by the H2020 European Union project "TrAM-Transport: Advanced and Modular" (contract 769303). The authors affiliated with the MSRC greatly acknowledge the funding from DNV and Royal Caribbean Group for the MSRC's establishment and operation. The opinions expressed herein are those of the authors and do not reflect the views of DNV and Royal Caribbean Group. Results of CFD simulations run by the University of Strathclyde were obtained using ARCHIE-WeSt High Performance Computer (www.archie-west.ac.uk (accessed on 23 April 2021)). 
Conflicts of Interest: The authors declare no conflict of interest.

\section{Nomenclature}

$\begin{array}{ll}b & \text { Breadth of the demihull } \\ B & \text { Breadth of the catamaran } \\ C_{T} & \text { Total resistance coefficient } \\ C_{F} & \text { Frictional resistance coefficient } \\ C_{F, I T T C} & \text { Frictional resistance coefficient calculated according to ITTC 1957 correlation line formula } \\ C_{P} & \text { Pressure resistance coefficient } \\ F n & \text { Froude number } \\ F n_{H} & \text { Depth Froude number } \\ g & \text { Gravity acceleration } \\ H & \text { Water depth } \\ L_{p p} & \text { Length between perpendiculars } \\ R e & \text { Reynolds number } \\ R_{T} & \text { Total resistance } \\ R_{F} & \text { Frictional resistance } \\ R_{P} & \text { Pressure resistance } \\ S & \text { Separation distance between the demihulls } \\ S_{S w} & \text { Static wetted surface area } \\ S_{d w} & \text { Dynamic wetted surface area } \\ T & \text { Draught } \\ U & \text { Ship speed relative to the incoming flow } \\ \sigma & \text { Sinkage } \\ \theta & \text { Trim } \\ \text { AP } & \text { Aft Perpendicular } \\ \text { CFD } & \text { Computational Fluid Dynamics } \\ \text { FP } & \text { Forward Perpendicular } \\ \text { HSVA } & \text { Hamburg Ship Model Basin } \\ \text { ITTC } & \text { International Towing Tank Committee } \\ \text { LCG } & \text { Longitudinal centre of gravity } \\ \text { MSRC } & \text { Maritime Safety Research Centre } \\ \text { VCG } & \text { Vertical centre of gravity } \\ & \end{array}$

\section{References}

1. Papanikolaou, A.D. Review of the Design and Technology Challenges of Zero-Emission, Battery-Driven Fast Marine Vehicles J. Mar. Sci. Eng. 2020, 8, 941. [CrossRef]

2. Papanikolaou, A.; Xing-Kaeding, Y.; Strobel, J.; Kanellopoulou, A.; Zaraphonitis, G.; Tolo, E. Numerical and Experimental Optimization Study on a Fast, Zero Emission Catamaran. J. Mar. Sci. Eng. 2020, 8, 657. [CrossRef]

3. Mittendorf, M.; Papanikolaou, A.D. Hydrodynamic Hull Form Optimization of Fast Catamarans Using Surrogate Models. Ship Technol. Res. 2021, 68, 14-26. [CrossRef]

4. Wang, H.; Boulougouris, E.; Theotokatos, G.; Priftis, A.; Shi, G.; Dahle, M.; Tolo, E. Risk Assessment of a Battery-Powered High-Speed Ferry Using Formal Safety Assessment. Safety 2020, 6, 39. [CrossRef]

5. Molland, A.F.; Wellicome, J.F.; Couser, P.R. Theoretical prediction of the wave resistance of slender hull forms in catamaran configurations. In Ship Science Report 72; University of Southampton: Southampton, UK, 1994.

6. Shahjada Tarafder, M.; Suzuki, K. Computation of Wave-Making Resistance of a Catamaran in Deep Water Using a Potential-Based Panel Method. Ocean Eng. 2007, 34, 1892-1900. [CrossRef]

7. Bari, G.S.; Matveev, K.I. Hydrodynamic Modeling of Planing Catamarans with Symmetric Hulls. Ocean Eng. 2016, 115, 60-66. [CrossRef]

8. Insel, M.; Molland, A.F. An Investigation into the Resistance Components of High Speed Displacement Catamarans. R. Inst. Nav. Archit. 1992, 134, 1-20.

9. Molland, A.F.; Wellicome, J.F.; Couser, P.R. Resistance experiments on a systematic series of high speed displacement catamaran forms: Variation of length-displacement ratio and breadth-draught ratio. In Ship Science Report 71; University of Southampton: Southampton, UK, 1994.

10. Zaraphonitis, G.; Spanos, D.; Papanikolaou, A. Numerical and Experimental Study on the Wave Resistance of Fast Displacement Asymmetric Catamarans. In Proceedings of the International Conference on High-Performance Marine Vehicles, Hamburg, Germany, 2-5 May 2001. 
11. Van't Veer, R. Experimental results of motions hydrodynarnic coefficients and wave loads on the 372 catamaran model. In Report 1129; Deift University of Technology: Delft, The Netherlands, 1998.

12. Broglia, R.; Bouscasse, B.; Jacob, B.; Olivieri, A.; Zaghi, S.; Stern, F. Calm Water and Seakeeping Investigation for a Fast Catamaran. In Proceedings of the 11th International Conference on Fast Sea Transportation, FAST 2011, Honolulu, HI, USA, 26-29 September 2011; pp. 336-344.

13. Broglia, R.; Jacob, B.; Zaghi, S.; Stern, F.; Olivieri, A. Experimental Investigation of Interference Effects for High-Speed Catamarans. Ocean Eng. 2014, 76, 75-85. [CrossRef]

14. Bouscasse, B.; Broglia, R.; Stern, F. Experimental Investigation of a Fast Catamaran in Head Waves. Ocean Eng. 2013, 72, 318-330. [CrossRef]

15. Durante, D.; Broglia, R.; Diez, M.; Olivieri, A.; Campana, E.F.; Stern, F. Accurate Experimental Benchmark Study of a Catamaran in Regular and Irregular Head Waves Including Uncertainty Quantification. Ocean Eng. 2019, 195, 106685. [CrossRef]

16. Falchi, M.; Felli, M.; Grizzi, S.; Aloisio, G.; Broglia, R.; Stern, F. SPIV Measurements around the DELFT 372 Catamaran in Steady Drift. Exp. Fluids 2014, 55. [CrossRef]

17. Zaraphonitis, G.; Papanikolaou, A.; Mourkogiannis, D. Hull form optimization of high speed vessels with respect to wash and powering. In Proceedings of the 8th International Conference on Marine Design (IMDC), Athens, Greece, 5-8 May 2003.

18. Souto-Iglesias, A.; Zamora-Rodríguez, R.; Fernández-Gutiérrez, D.; Pérez-Rojas, L. Analysis of the Wave System of a Catamaran for CFD Validation. Exp. Fluids 2007, 42, 321-332. [CrossRef]

19. Souto-Iglesias, A.; Fernández-Gutiérrez, D.; Pérez-Rojas, L. Experimental Assessment of Interference Resistance for a Series 60 Catamaran in Free and Fixed Trim-Sinkage Conditions. Ocean Eng. 2012, 53, 38-47. [CrossRef]

20. Danişman, D.B. Reduction of Demi-Hull Wave Interference Resistance in Fast Displacement Catamarans Utilizing an Optimized Centerbulb Concept. Ocean Eng. 2014, 91, 227-234. [CrossRef]

21. Broglia, R.; Zaghi, S.; Campana, E.F.; Dogan, T.; Sadat-Hosseini, H.; Stern, F.; Queutey, P.; Visonneau, M.; Milanov, E. Assessment of Computational Fluid Dynamics Capabilities for the Prediction of Three-Dimensional Separated Flows: The Delft 372 Catamaran in Static Drift Conditions. J. Fluids Eng. 2019, 141, 1-28. [CrossRef]

22. Choi, J.E.; Min, K.S.; Kim, J.H.; Lee, S.B.; Seo, H.W. Resistance and Propulsion Characteristics of Various Commercial Ships Based on CFD Results. Ocean Eng. 2010, 37, 549-566. [CrossRef]

23. Liefvendahl, M.; Fureby, C. Grid Requirements for LES of Ship Hydrodynamics in Model and Full Scale. Ocean Eng. 2017, 143, 259-268. [CrossRef]

24. Romanowski, A.; Tezdogan, T.; Turan, O. Development of a CFD Methodology for the Numerical Simulation of Irregular Sea-States. Ocean Eng. 2019, 192, 106530. [CrossRef]

25. Castiglione, T.; Stern, F.; Bova, S.; Kandasamy, M. Numerical Investigation of the Seakeeping Behavior of a Catamaran Advancing in Regular Head Waves. Ocean Eng. 2011, 38, 1806-1822. [CrossRef]

26. He, W.; Diez, M.; Zou, Z.; Campana, E.F.; Stern, F. URANS Study of Delft Catamaran Total/Added Resistance, Motions and Slamming Loads in Head Sea Including Irregular Wave and Uncertainty Quantification for Variable Regular Wave and Geometry. Ocean Eng. 2013, 74, 189-217. [CrossRef]

27. Jamaluddin, A.; Utama, I.K.A.P.; Widodo, B.; Molland, A.F. Experimental and Numerical Study of the Resistance Component Interactions of Catamarans. J. Eng. Marit. Environ. 2013, 227, 51-60. [CrossRef]

28. Yengejeh, M.A.; Amiri, M.M.; Mehdigholi, H.; Seif, M.S.; Yaakob, O. Numerical Study on Interference Effects and Wetted Area Pattern of Asymmetric Planing Catamarans. J. Eng. Marit. Environ. 2016, 230, 417-433. [CrossRef]

29. Zha, R.S.; Ye, H.X.; Shen, Z.R.; Wan, D.C. Numerical Computations of Resistance of High Speed Catamaran in Calm Water. J. Hydrodyn. 2015, 26, 930-938. [CrossRef]

30. Zaghi, S.; Broglia, R.; Di Mascio, A. Analysis of the Interference Effects for High-Speed Catamarans by Model Tests and Numerical Simulations. Ocean Eng. 2011, 38, 2110-2122. [CrossRef]

31. Broglia, R.; Zaghi, S.; Di Mascio, A. Numerical Simulation of Interference Effects for a High-Speed Catamaran. J. Mar. Sci. Technol. 2011, 16, 254-269. [CrossRef]

32. He, W.; Castiglione, T.; Kandasamy, M.; Stern, F. Numerical Analysis of the Interference Effects on Resistance, Sinkage and Trim of a Fast Catamaran. J. Mar. Sci. Technol. 2015, 20, 292-308. [CrossRef]

33. Haase, M.; Zurcher, K.; Davidson, G.; Binns, J.R.; Thomas, G.; Bose, N. Novel CFD-Based Full-Scale Resistance Prediction for Large Medium-Speed Catamarans. Ocean Eng. 2016, 111, 198-208. [CrossRef]

34. Farkas, A.; Degiuli, N.; Martić, I. Numerical Investigation into the Interaction of Resistance Components for a Series 60 Catamaran. Ocean Eng. 2017, 146, 151-169. [CrossRef]

35. Ferreiro, L.D. The Effects of Confined Water Operations on Ship Performance: A Guide for the Perplexed. Nav. Eng. J. 1992, 104, 69-83. [CrossRef]

36. Jachowski, J. Assessment of Ship Squat in Shallow Water Using CFD. Arch. Civ. Mech. Eng. 2008, 8, 27-36. [CrossRef]

37. Tezdogan, T.; Incecik, A.; Turan, O. A Numerical Investigation of the Squat and Resistance of Ships Advancing through a Canal Using CFD. J. Mar. Sci. Technol. 2016, 21, 86-101. [CrossRef]

38. Terziev, M.; Tezdogan, T.; Oguz, E.; Gourlay, T.; Demirel, Y.K.; Incecik, A. Numerical Investigation of the Behaviour and Performance of Ships Advancing through Restricted Shallow Waters. J. Fluids Struct. 2018, 76, 185-215. [CrossRef] 
39. Feng, D.; Ye, B.; Zhang, Z.; Wang, X. Numerical Simulation of the Ship Resistance of KCS in Different Water Depths for Model-Scale and Full-Scale. J. Mar. Sci. Eng. 2020, 8, 745. [CrossRef]

40. Chen, X.N.; Sharma, S.D.; Stuntz, N. Wave Reduction by S-Catamaran at Supercritical Speeds. J. Ship Res. 2003, 47, 145-154. [CrossRef]

41. Castiglione, T.; He, W.; Stern, F.; Bova, S. Effects of Shallow Water on Catamaran Interference. In Proceedings of the 11th International Conference on Fast Sea Transportation, FAST 2011, Honolulu, HI, USA, 26-29 September 2011; pp. 371-376.

42. Moraes, H.B.; Vasconcellos, J.M.; Latorre, R.G. Wave Resistance for High-Speed Catamarans. Ocean Eng. 2004, 31, $2253-2282$. [CrossRef]

43. Zhu, Y.; Ma, C.; Wu, H.; He, J.; Zhang, C.; Li, W.; Noblesse, F. Farfield Waves Created by a Catamaran in Shallow Water. Eur. J. Mech. B/Fluids 2016, 59, 197-204. [CrossRef]

44. Molland, A.F.; Wilson, P.A.; Taunton, D.J. A systematic series of experimental wash wave measurements for high speed displacement monohull and catamaran forms in shallow water. In Ship Science Report 122; University of Southampton: Southampton, UK, 2001. [CrossRef]

45. Molland, A.F.; Wilson, P.A.; Taunton, D.J. Resistance experiments on a systematic series of high speed displacement monohull and catamaran forms in shallow water. In Ship Science Report 127; University of Southampton: Southampton, UK, 2003.

46. Gourlay, T. Sinkage and Trim of a Fast Displacement Catamaran in Shallow Water. J. Ship Res. 2008, 52, 175-183. [CrossRef]

47. Lee, S.H.; Lee, Y.G.; Kim, S.H. On the Development of a Small Catamaran Boat. Ocean Eng. 2007, 34, 2061-2073. [CrossRef]

48. Castiglione, T.; He, W.; Stern, F.; Bova, S. URANS Simulations of Catamaran Interference in Shallow Water. J. Mar. Sci. Technol. 2014, 19, 33-51. [CrossRef]

49. Ferziger, J.H.; Peric, M.; Street, R.L. Computational Methods for Fluid Dynamics, 4th ed.; Springer Nature Switzerland: Cham, Switzerland, 2020.

50. Stern, S.; Wilson, R.; Shao, J. Quantitative V\&V of CFD simulations and certification of CFD codes. Int. J. Numer. Methods Fluids 2006, 50, 1335-1355.

51. Gatchell, S.; Hafermann, D.; Streckwall, H. Open Water Test Propeller Performance and Cavitation Behaviour Using PPB and FreSCo+. In Proceedings of the Second International Symposium on Marine Propulsors, Hamburg, Germany, 15-17 June 2011. 